SANDIA REPORT

SAND95-2791 • UC-703

Unlimited Release

Printed December 1995
RECEIVED

\author{
JAN 251996
}

OSTI

\title{
Nonlocal Effects on Dynamic Damage Accumulation in Brittle Solids
}

\section{E. P. Chen}

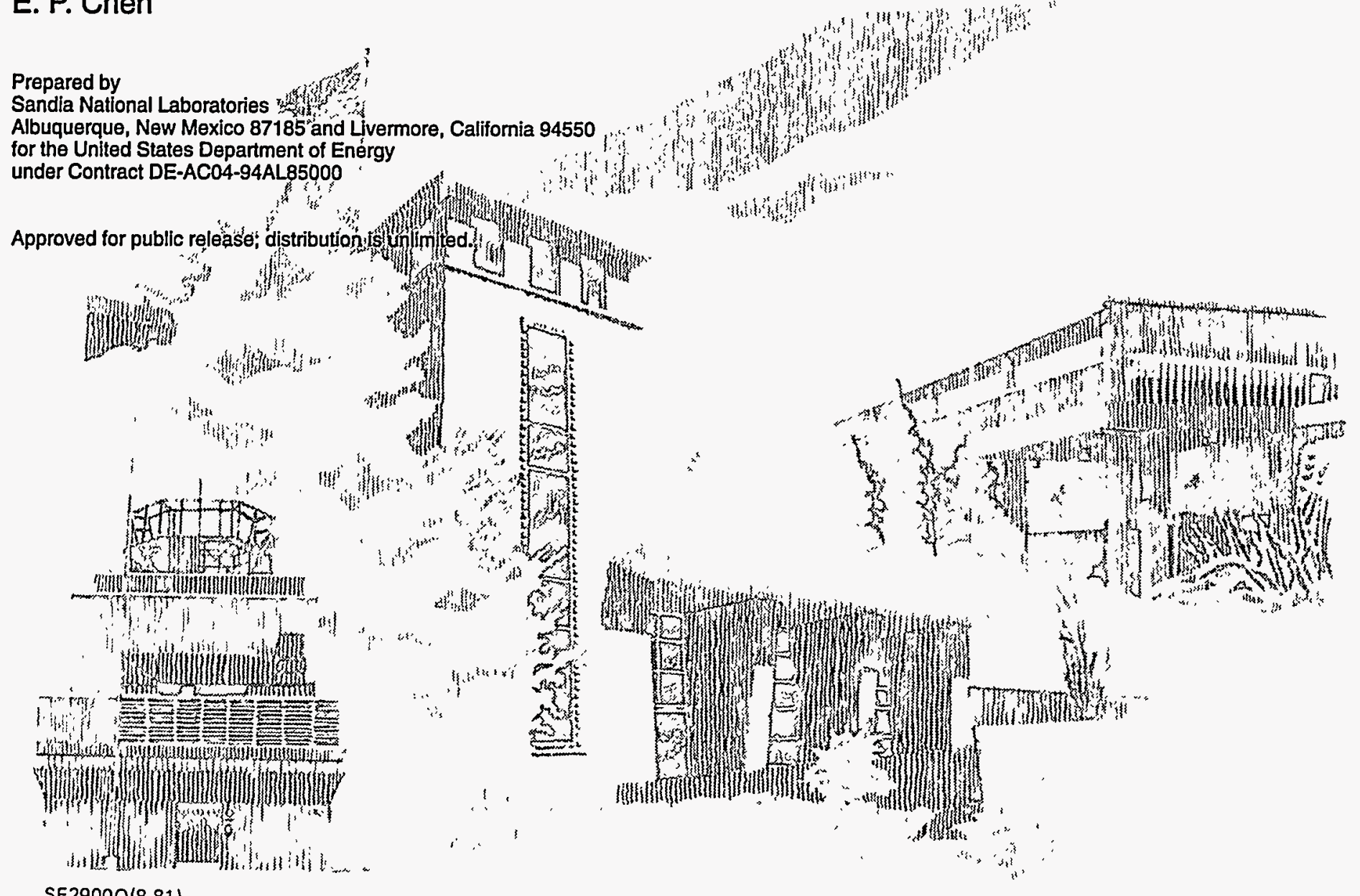

\section{旅ASTER}

DISTRIBUTION OF THLS DOCUMENT IS HAHLARTED 
Issued by Sandia National Laboratories, operated for the United States Department of Energy by Sandia Corporation.

NOTICE: This report was prepared as an account of work sponsored by an agency of the United States Government. Neither the United States Government nor any agency thereof, nor any of their employees, nor any of their contractors, subcontractors, or their employees, makes any warranty, express or implied, or assumes any legal liability or responsibility for the accuracy, completeness, or usefulness of any information, apparatus, product, or process disclosed, or represents that its use would not infringe privately owned rights. Reference herein to any specific commercial product, process, or service by trade name, trademark, manufacturer, or otherwise, does not necessarily constitute or imply its endorsement, recommendation, or favoring by the United States Government, any agency thereof or any of their contractors or subcontractors. The views and opinions expressed herein do not necessarily state or reflect those of the United States Government, any agency thereof or any of their contractors.

Printed in the United States of America. This report has been reproduced directly from the best available copy.

Available to DOE and DOE contractors from

Office of Scientific and Technical Information

PO Box 62

Oak Ridge, TN 37831

Prices available from (615) 576-8401, FTS 626-8401

Available to the public from

National Technical Information Service

US Department of Commerce

5285 Port Royal Rd

Springfield, VA 22161

NTIS price codes

Printed copy: A03

Microfiche copy: A01 


\title{
Nonlocal Effects on Dynamic Damage Accumulation in Brittle Solids
}

\author{
E.P. Chen \\ Material and Structural Mechanics Department \\ Sandia National Laboratories \\ Albuquerque, New Mexico 87185-0437
}

\begin{abstract}
This paper presents a nonlocal analysis of the dynamic damage accumulation processes in brittle solids. A nonlocal formulation of a microcrack based continuum damage model is developed and implemented into a transient dynamic finite element computer code. The code is then applied to the study of the damage accumulation process ina concrete plate with a central hole and subjected to the action of a step tensile pulse applied at opposite edges of the plate. Several finite element discretizations are used to examine the mesh size effect. Comparisons between calculated results based on local and nonlocal formulations are made and nonlocal effects are discussed.
\end{abstract}




\section{Acknowledgments}

This work was funded by the Laboratory Directed Research and Development Program, Sandia National Laboratories, under the auspices of the U. S. Department of Energy under Contract Number DE-AC04-94AL85000. 


\section{Contents}

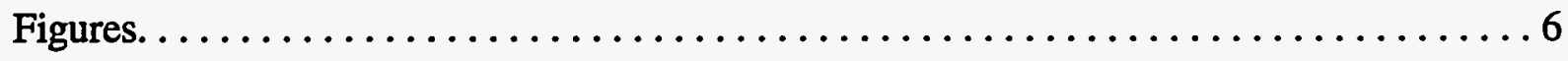

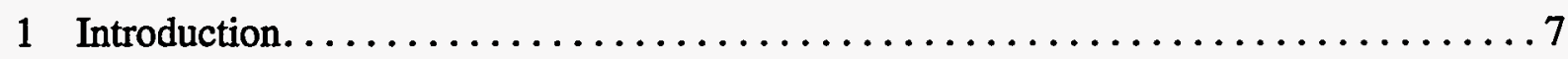

2 Continuum damage model description $\ldots \ldots \ldots \ldots \ldots \ldots \ldots \ldots \ldots \ldots$

3 Characteristics of the damage model $\ldots \ldots \ldots \ldots \ldots \ldots \ldots \ldots \ldots \ldots$

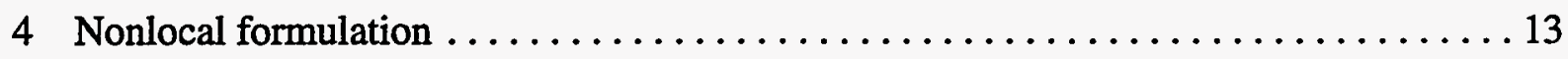

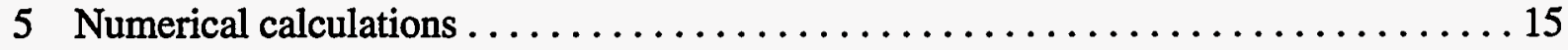

6 Summary and discussions. . . . . . . . . . . . . . . . . . 18

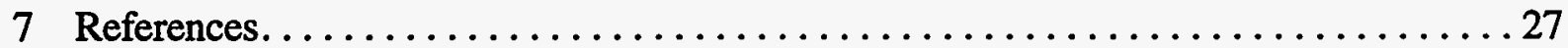




\section{Figures}

Figure 1. Oil Shale tensile fracture stress versus strain rate data. $\ldots \ldots \ldots \ldots \ldots \ldots$

Figure 2. Oil Shale bulk response under tension...................... 11

Figure 3. Damage versus volumetric strain plot. $\ldots \ldots \ldots \ldots \ldots \ldots \ldots \ldots \ldots \ldots$

Figure 4. Cyclic bulk tension response of Oil Shale $\ldots \ldots \ldots \ldots \ldots \ldots \ldots \ldots \ldots$

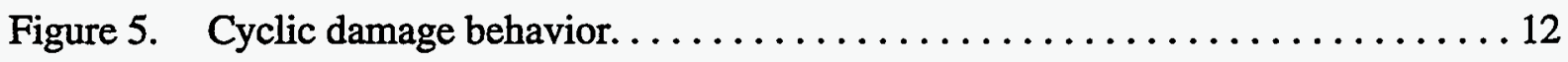

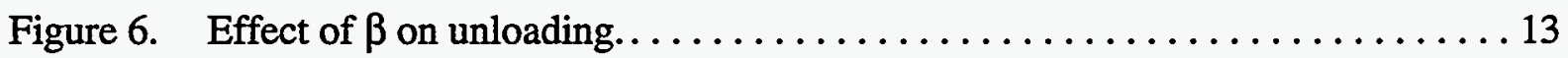

Figure 7. Schematic drawing of the example problem. ................. 15

Figure 8. Finite element mesh with 75 elements.................... 17

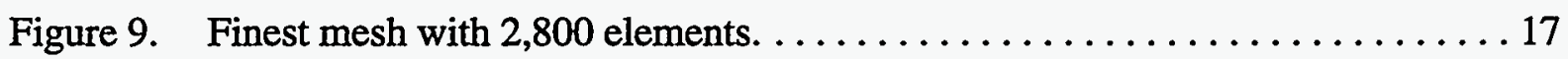

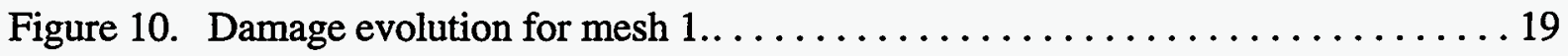

Figure 11. Damage evolution for mesh $2 \ldots \ldots \ldots \ldots \ldots \ldots \ldots \ldots \ldots \ldots \ldots \ldots \ldots \ldots \ldots \ldots \ldots$

Figure 12. Damage evolution for mesh $3 \ldots \ldots \ldots \ldots \ldots \ldots \ldots \ldots \ldots \ldots \ldots \ldots \ldots \ldots \ldots \ldots \ldots \ldots$

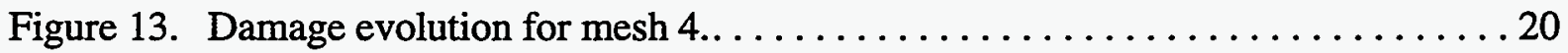

Figure 14. Bulk strain distribution at $0.175 \mathrm{~ms} . \ldots \ldots \ldots \ldots \ldots \ldots \ldots \ldots \ldots \ldots \ldots \ldots$

Figure 15. Bulk strain distribution at $0.2 \mathrm{~ms} \ldots \ldots \ldots \ldots \ldots \ldots \ldots \ldots \ldots \ldots \ldots \ldots \ldots \ldots$

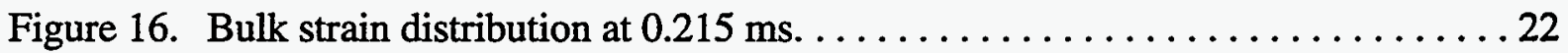

Figure 17. Bulk strain distribution at $0.225 \mathrm{~ms} \ldots \ldots \ldots \ldots \ldots \ldots \ldots \ldots \ldots \ldots \ldots \ldots \ldots \ldots \ldots$

Figure 18. Nonlocal damage evolution for mesh $1 \ldots \ldots \ldots \ldots \ldots \ldots \ldots \ldots \ldots \ldots$

Figure 19. Nonlocal damage evolution for mesh $2 \ldots \ldots \ldots \ldots \ldots \ldots \ldots \ldots \ldots \ldots \ldots$

Figure 20. Nonlocal damage evolution for mesh $3 \ldots \ldots \ldots \ldots \ldots \ldots \ldots \ldots \ldots \ldots$

Figure 21. Nonlocal damage evolution for mesh $4 \ldots \ldots \ldots \ldots \ldots \ldots \ldots \ldots \ldots$

Figure 22. Nonlocal bulk strain distribution at $0.175 \mathrm{~ms} \ldots \ldots \ldots \ldots \ldots \ldots \ldots \ldots \ldots \ldots \ldots$

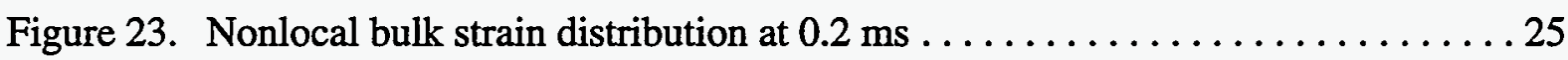

Figure 24. Nonlocal bulk strain distribution at $0.215 \mathrm{~ms} \ldots \ldots \ldots \ldots \ldots \ldots \ldots$

Figure 25. Nonlocal bulk strain distribution at $0.225 \mathrm{~ms} \ldots \ldots \ldots \ldots \ldots \ldots \ldots \ldots$ 


\subsection{INTRODUCTION}

Continuous demands on safety and efficient design have placed increasing emphases on fracture and failure analyses of engineering materials and structures. Continuum damage mechanics have been applied to study the phenomenon of brittle fracture in solids under dynamic loads with varying degrees of success [1-6]. Because of the complex geometries and loading conditions involved, numerical simulation techniques have become the tools of choice. Two common problems associated with damage analyses by classical continuum damage mechanics are softening and localization. The consequences of failing to take into account these two problems properly usually manifested in solutions which are dependent on the discretization size. A potential remedy is to cast the field equations in a nonlocal setting such that the high gradients associated with the field parameters in these problems can be captured. The nonlocality is usually represented by an internal length scale which can be introduced in formulations ranging from the Cosserat and micropolar theories $[7,8]$, the gradient theory $[9,10]$, fully nonlocal $[11,12]$ and partially nonlocal [13] representations.

The purpose of this research is to investigate the appropriateness of applying nonlocal damage models to analyze dynamic brittle fracture. The study is based on the comparisons between numerical results obtained from the same damage model with both a nonlocal and a local formulation. The damage model selected is the one developed by the author and his coworkers [16] to simulate brittle rock fracturing. A nonlocal version is developed here by utilizing the nonlocal formulation suggested in [13] in which nonlocality is only applied to those internal state variables involved with material damage. The model has been implemented into the transient finite element code PRONTO 2D [14] for numerical analysis. An example problem has been defined and results have been obtained from both local and nonlocal calculations. To examine mesh size effect, several discretizations are used in the numerical computations. Comparisons between these results have been made. Based on these findings, it is clear that mesh size dependence can be alleviated by adopting a nonlocal damage model formulation. However, the determination of the internal length scale associate with the nonlocal formulation is certainly nontrivial. Moreover, nonlocality tends to smear out localized deformations and thus may suppress truly local failure modes. This may render the nonlocal models inappropriate for predicting localized failure mechanisms.

\subsection{CONTINUUM DAMAGE MODEL DESCRIPTION}

The basic assumption of the damage model is that the material is permeated by an array of randomly distributed cracks which grow and interact with one another under tensile loading. The model does not attempt to treat each individual crack, but rather treats the growth and interaction of cracks as internal state variables which represent damage accumulation in the material. The damage is reflected in the degradation of the material stiffness following the equations derived by Budiansky and $O^{\prime}$ Connell [15] for a random array of penny-shaped cracks in an isotropic elastic medium

$$
\frac{\bar{K}}{K}=1-\frac{16}{9}\left(\frac{1-\bar{v}^{2}}{1-2 \bar{v}}\right) C_{d}
$$




$$
\begin{aligned}
& \frac{\bar{G}}{\bar{G}}=1-\frac{32}{45} \frac{(1-\bar{v})(5-\bar{v})}{(2-\bar{v})} C_{d} \\
& \frac{\bar{E}}{E}=1-\frac{16}{45} \frac{\left(1-\bar{v}^{2}\right)(10-3 \bar{v})}{(2-\bar{v})} C_{d}
\end{aligned}
$$

where $\mathrm{K}, \mathrm{G}, \mathrm{E}$ and $v$ are material bulk modulus, shear modulus, Young modulus and Poisson's ratio, respectively. Barred quantities such as $\overline{\mathrm{K}}$ represent degraded properties and $C_{d}$ is the crack density parameter. Additionally, the crack density parameter is related to the virgin and damaged Poisson's ratio through:

$$
C_{d}=\frac{45}{16} \frac{(v-\bar{v})(2-\bar{v})}{\left(1-\bar{v}^{2}\right)[10 v-\bar{v}(1+3 v)]}
$$

The damage variable is defined as

$$
D=\frac{16}{9}\left(\frac{1-\overline{\mathrm{v}}^{2}}{1-2 \overline{\mathrm{v}}}\right) C_{d}
$$

such that $\overline{\mathrm{K}}=\mathrm{K}(1-\mathrm{D})$. The crack density parameter is assumed to be proportional to the product of $\mathrm{N}$, the number of cracks per unit volume, and $\mathrm{a}^{3}$, the cube of the average crack dimension in a representative volume. Following Grady and Kipp [16], $\mathrm{N}$ is expressed as a Weibull statistical distribution function activated by the bulk strain measure $\varepsilon_{v}=\left(\varepsilon_{x}+\varepsilon_{y}+\varepsilon_{z}\right) / 3$, according to

$$
N=k\left(\varepsilon_{v}\right)^{m}
$$

in which $\mathrm{k}$ and $\mathrm{m}$ are material constants to be determined from strain rate dependent tensile fracture stress data. The average crack dimension a, is estimated from the nominal fragment diameter for dynamic fragmentation in a brittle material [17] as

$$
2 a=\left(\frac{\sqrt{20} K_{I C}}{\rho C \dot{\varepsilon}_{v \max }}\right)^{\frac{2}{3}}
$$

where $\rho$ is the mass density, $C$ is the uniaxial wave speed $(E / \rho)^{1 / 2}$, and $K_{I C}$ is the fracture toughness of the material. Also, $\dot{\varepsilon}_{v m a x}$ is the maximum volumetric strain rate experienced by the representative volume element. Equations (1) through (5) can also be cast into rate form to relate stress and strain rates. When bulk tension occurs in the material, it is possible to calculate, at each time step, the crack density parameter $C_{d}$ by making use of Equations (6) and (7) and then dam- 
age parameter D through Equation (5). The material stiffness is then degraded according to Equations (1) through (5). In compression, the material behaves as an elastic/perfectly plastic solid. Details of the model development are given in Taylor, Chen and Kuszmaul [1] and will not be repeated here.

Modifications have been made to the above model to render it a more versatile tool. Because the equations derived by Budiansky and O'Connell [15] are limited to dilute crack concentrations, the crack density parameter has a limiting value of $9 / 16$. To extend the range of crack densities, an expression [18]

$$
\bar{v}=v e^{\frac{16}{9} \beta C_{d}}, \quad 0 \leq \beta \leq 1
$$

was used to approximate Equation (4). Equation (8) recovers Budiansky and O'Connell's expression for dilute crack concentrations at small crack density $C_{d}$ and attains the correct limit of zero stiffness for large $C_{d}$ values. In comparison with the expression in [1], the crack density parameter $16 C_{d} / 9$ is effectively replaced by $1-e^{-\frac{16}{9} \beta C_{d}}$.The value of $\beta$ controls the unloading and reloading behavior and relaxes the restriction of elastic unloading in the original model.

For many brittle solids, pressure-dependent inelastic response under compressive loads is observed. An improvement is made by extending the elastic/perfectly plastic compressive response to one that employs a Drucker-Prager yield surface [19]:

$$
\bar{F}=\bar{\sigma}^{2}-\left(c_{1}+c_{2} P\right)^{2}=0
$$

with $\bar{\sigma}$ the effective stress, $P$ the mean stress and $c_{1}$ and $c_{2}$ material constants determined from experimental data. To avoid too much dilation, a von Mises flow rule of the type

$$
\dot{\varepsilon}_{i j}^{p}=\dot{\lambda} \frac{s_{i j}}{\sqrt{s_{i j} s_{i j}}}
$$

is adopted. In Equation (10), $\dot{\varepsilon}_{i j}^{p}$ is the plastic strain rate tensor, $\dot{\lambda}$ is the plastic loading rate parameter, and $s_{i j}$ is the deviatoric stress tensor.

\subsection{CHARACTERISTICS OF THE DAMAGE MODEL}

Characteristics of the continuum damage model described are examined here for the same oil shale as in [1]. Nominal material properties such as the mass density, the Young's modulus, the Poisson's ratio and the fracture toughness are taken to be $2270 \mathrm{~kg} / \mathrm{m}^{3}, 10.8 \mathrm{GPa}$, 
0.2 and $1.0 \mathrm{MPa}-\mathrm{m}^{1 / 2}$, respectively. Shear strength $\tau$ was approximated by a linear relationship of $\tau=200.0+0.5 \mathrm{P}(\mathrm{MPa})$. Strain-rate dependent tensile fracture stress data are required to determine the constants $\mathrm{k}$ and $\mathrm{m}$ in Equation (6). In lieu of measured data, it is possible to estimate this data using an expression derived in Kipp, Grady and Chen [20] for the tensile fracture stress $\sigma_{\mathrm{c}}$ :

$$
\sigma_{c}=\left(\frac{9 \pi E K_{I C}^{2}}{16 N_{s}^{2} C_{s}}\right)^{\frac{1}{3}} \frac{1}{\dot{\varepsilon}^{3}}
$$

where $\mathrm{N}_{\mathrm{s}}$ is a shape factor (1.12 for penny-shaped cracks) and $\mathrm{C}_{\mathrm{s}}$ is the shear wave velocity of the material. Thus, $\mathrm{k}$ and $\mathrm{m}$ are really not additional material constants for the model. For the oil shale, Kipp and Grady [21] reported fracture stress versus strain rate data and this is shown in Fig. 1. Based on these data and the material properties given above, $\mathrm{m}$ and $\mathrm{k}$ are determined to be 7.0 and $5.11610^{22} / \mathrm{m}^{3}$, respectively.

Using these material properties and 0.5 for $\beta$, the response of the oil shale under bulk tension can now be examined. Fig. 2 shows the pressure-volumetric strain relationship under uniaxial homogeneous straining for three strain rates. In this figure, positive pressure denotes bulk tension. Strain-softening is observed as a consequence of the micro-cracking damage accumulation. The material's capability to carry bulk tension increases with the strain rate.

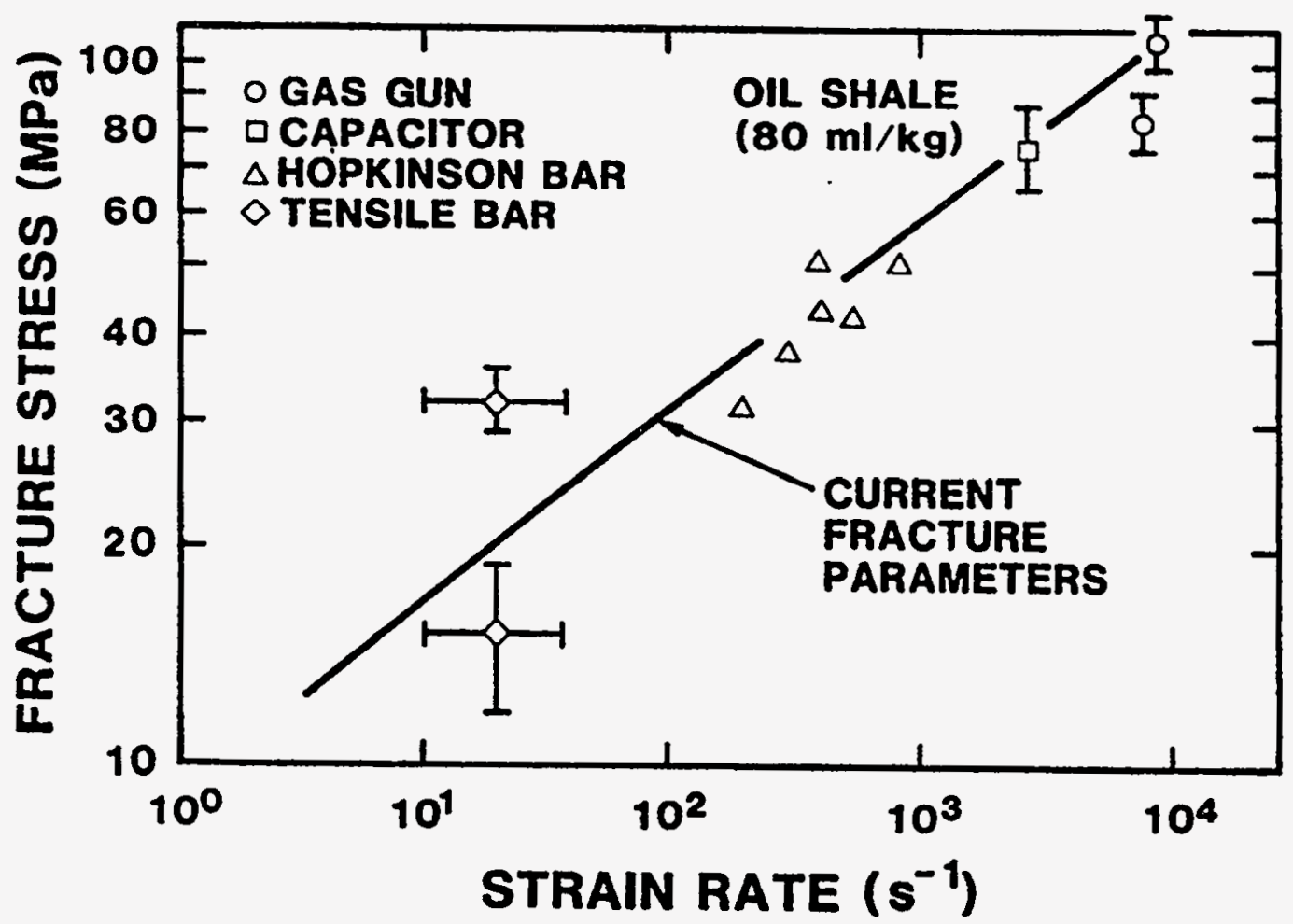

Figure 1. Oil Shale tensile fracture stress versus strain rate data. 


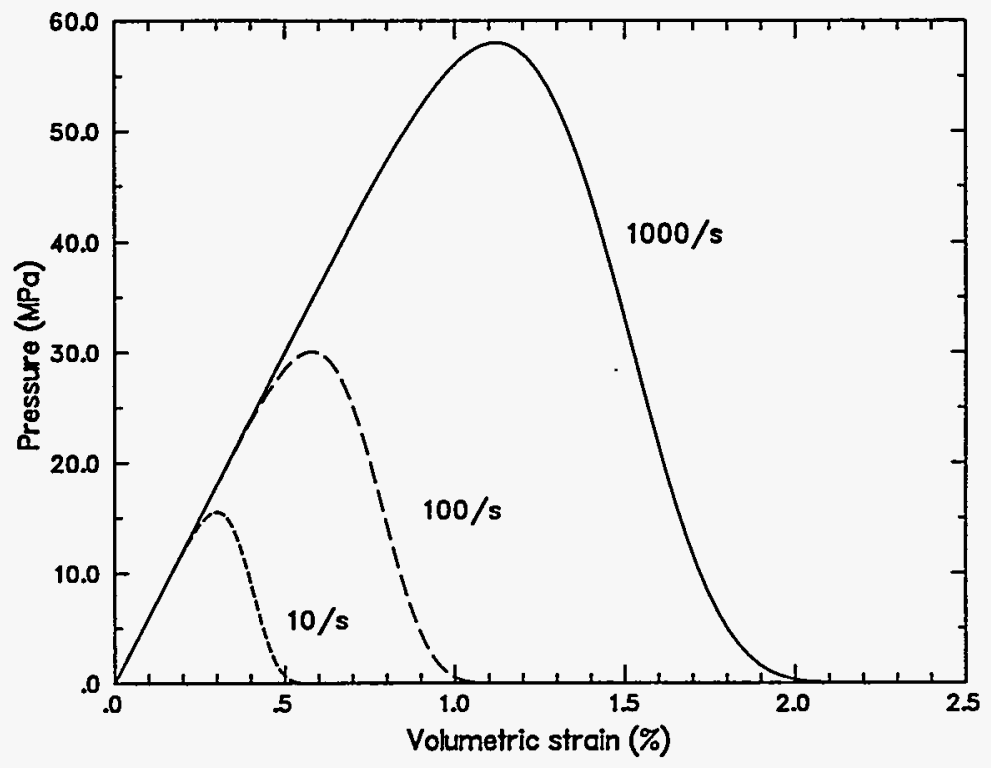

Figure 2. Oil Shale bulk response under tension.

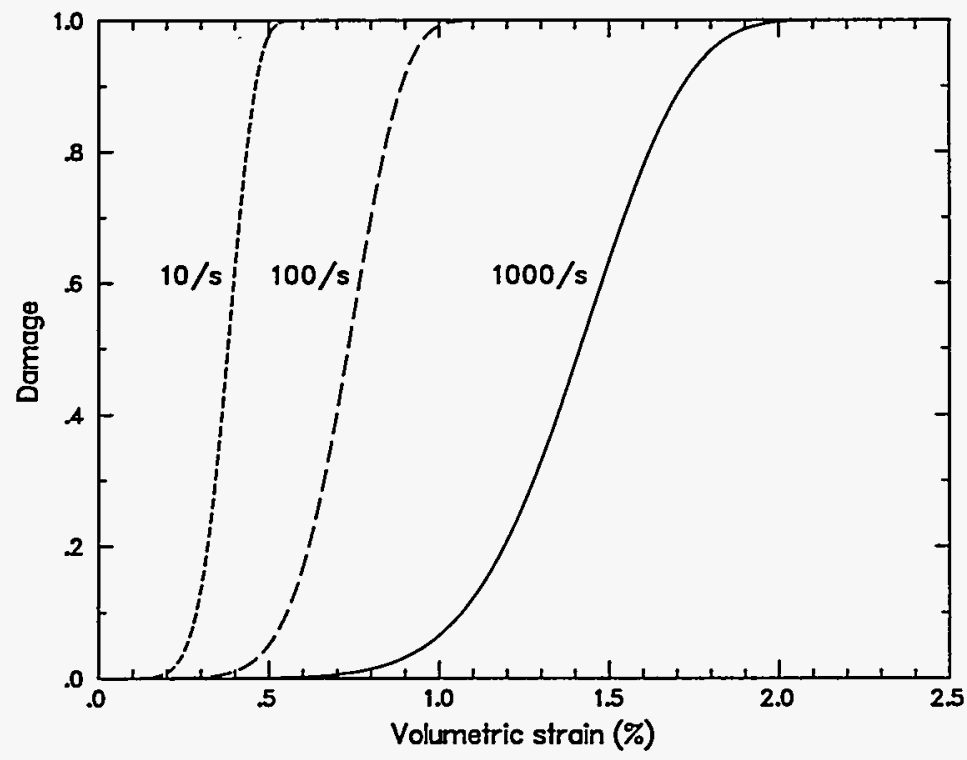

Figure 3. Damage versus volumetric strain plot. 


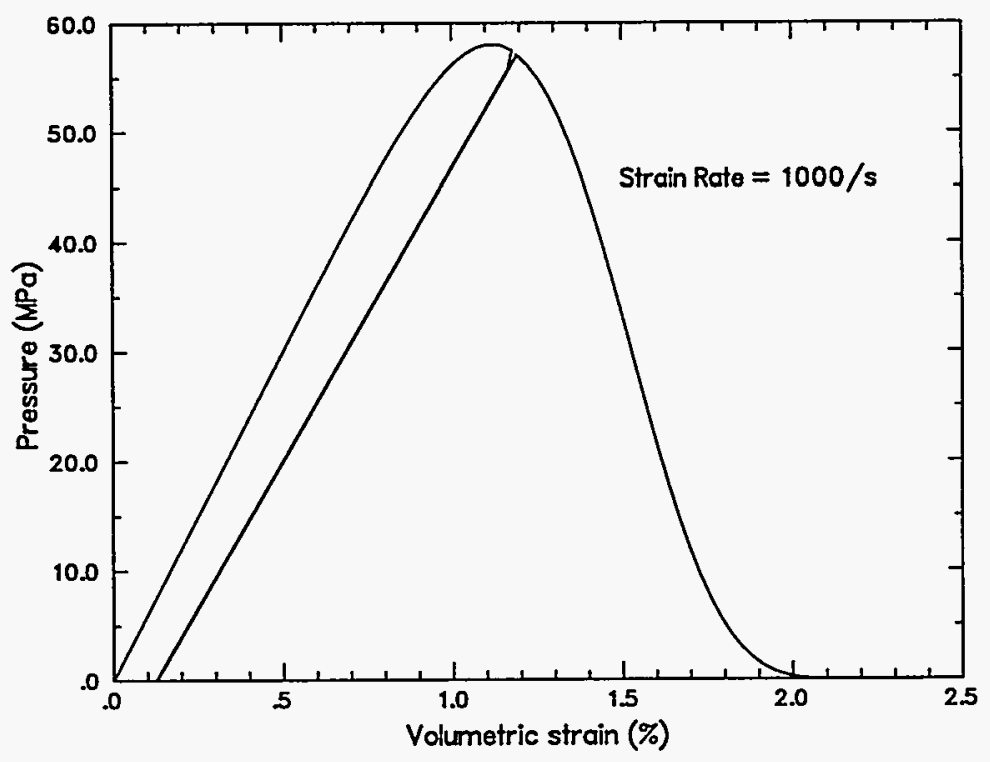

Figure 4. Cyclic bulk tension response of Oil Shale.

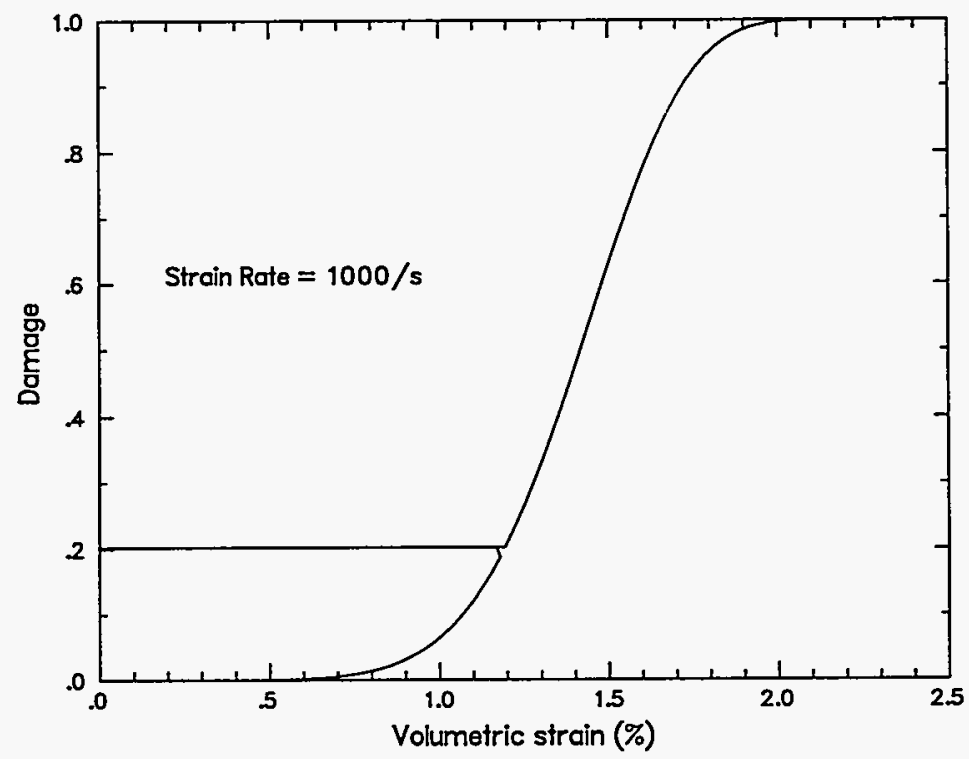

Figure 5. Cyclic damage behavior. 
Damage accumulation as a function of volumetric strain is shown in Fig. 3. The loading/ unloading/reloading behavior for 1000/s strain rate is exhibited in Fig. 4 and 5 in terms of the pressure- and damage-volumetric strain plot, respectively. It is seen that the damage evolution is an irreversible process. During reloading, no more damage accumulation will take place until the strain level have exceeded the previous maximum. The value for $\beta$ controls the unloading response. For $\beta=0$, elastic unloading along the damaged bulk modulus will result. For $\beta=1$, unloading is along the original bulk modulus similar to elastic/plastic behavior. For $\beta$ between 0 and 1, a combined damage/plastic unloading response results. The effect of $\beta$ is illustrated in Fig. 6. Note that because of the modifications, the numerical values reported here are slightly different from those in [1]. Also, the exponential representation in Equation (8) renders better numerical convergence and smooth softening responses.

\subsection{NONLOCAL FORMULATION}

Nonlocal formulations involve the introduction of localization limiters, usually an internal length scale, into classical continuum field equations. Depending on the degree of sophistication, several theories exist in the literature [7-13, 22]. The purpose of the present investigation is to examine general nonlocal effects and it suffices to consider a simple yet efficient formulation. To this end, the nonlocal continuum with local strain model [13] is adopted here. Typically, for this model, some of the variables in the constitutive equation are defined by spatial averaging while the others retain their local definitions. The spatial average of the magnitude of an arbitrary variable $\gamma$ at location $x$ may be defined by the equation

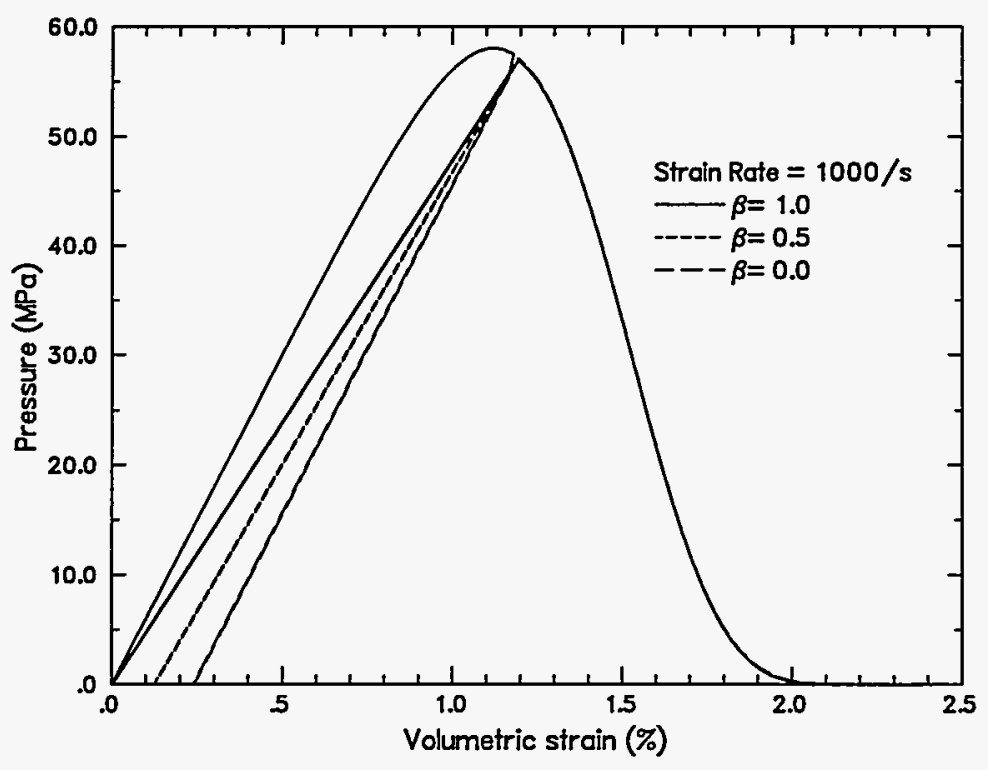

Figure 6. Effect of $\beta$ on unloading. 


$$
\langle\gamma(\underline{x})\rangle=\frac{1}{V_{r}(\underline{x})} \int_{V} \alpha(\underline{s}-\underset{x}{x}) \gamma(\underline{s}) d V
$$

in which

$$
V_{r}(\underline{x})=\int_{V} \alpha(\underline{s}-\underline{x}) d V
$$

The pointed brackets $\langle>$ denote the averaging operator, $V$ is the volume of the body, $\alpha(x)$ is the weighing function which defines the averaging, and $\underset{\sim}{s}$ is the general coordinate vector. The selection of the weighing function is based on numerical efficiency. The normal (Gaussian) distribution function (error density function)

$$
\alpha(x)=e^{-\frac{|x|^{2}}{4 l^{2}}}
$$

was selected in [13] for two-dimensional geometries. In Equation (14), $l$ is the characteristic length which is a material property that defines the diameter of the representative volume.

Judicious choices of the variables which should be subjected to spatial averaging are required. In [13], for a nonlocal plasticity model, only the plastic strain was subjected to spatial averaging and satisfactory results were obtained. Motivated by the results in [13], the present nonlocal formulation will apply spatial averaging to state variables relating to material damage while others maintain their local definitions. By analyzing Equations (1) - (8) and replacing the crack density parameter $16 C_{d} / 9$ with $1-e^{\frac{16}{9} \beta C_{d}}$, a mixed system of algebraic and ordinary differential equations can be constructed for the evolution of tensile damage as follows:

$$
\begin{aligned}
& \dot{C}_{d}=\frac{5 k m \varepsilon_{v}^{m-1}}{2}\left(\frac{K_{I C}}{\rho C \dot{\varepsilon}_{v \max }}\right)^{2} \dot{\varepsilon}_{v} \\
& D=\frac{1-\bar{v}^{2}}{1-2 \bar{v}}\left(1-e^{-\frac{16}{9} \beta C_{d}}\right) \\
& \bar{K}=K(1-D) \\
& \bar{G}=G\left[1-\frac{2}{5} \frac{(1-\bar{v})(5-\bar{v})}{(2-\bar{v})}\left(1-e^{-\frac{16}{9} \beta C_{d}}\right)\right]
\end{aligned}
$$




$$
\begin{aligned}
\dot{P} & =3 \bar{K} \dot{\varepsilon}_{v}-3 K \varepsilon_{v} \dot{D} \\
\dot{s}_{i j} & =2 \bar{G} \dot{e}_{i j}+2 \dot{\bar{G}} e_{i j}
\end{aligned}
$$

where $s_{i j}$ and $e_{i j}$ are the deviatoric stress and strain tensor, respectively and the dot superscript denotes differentiation with respect to time. Together with Equation (8), Equations (15)-(20) can be used to calculate the evolution of tensile damage in the material. For a given imposed state of deformation in a time or loading step, the crack density increment is calculated from Equation (15) and $C_{d}$ is updated to the end of the time step. The damage increment is obtained by differentiating Equation (16) and its value can be updated. It follows from Equations (8), (17) and (18) that the time rate and the degraded Poisson's ratio, bulk and shear modulus can be evaluated. Then, through Equations (19) and (20), the stress state is obtained. The state variables which affect the damage evolution are the crack density parameter $C_{d}$ and the damage variable $D$. Thus, spatial averaging based on Equations (12)-(14) is applied to $C_{d}$ and $D$ only while all other field variables retain their local definitions. In compression, local plasticity theory of the Prager-Drucker type governs the constitutive behavior of the material.

Without going into more details, this nonlocal damage model have been vectorized and implemented into the explicit finite element code PRONTO 2D [14] for efficient computations.

\subsection{NUMERICAL CALCULATIONS}

General nonlocal effects are examined based on the comparisons of results between local and nonlocal calculations. The example problem selected is the same one used in [6] which involves the sudden stretching of a plate with a centrally located hole. Consider the $0.2 \mathrm{~m}$ by $0.4 \mathrm{~m}$ rectangular plate with a $0.1 \mathrm{~m}$ diameter hole in the center in Fig. 7. A step tensile pulse is

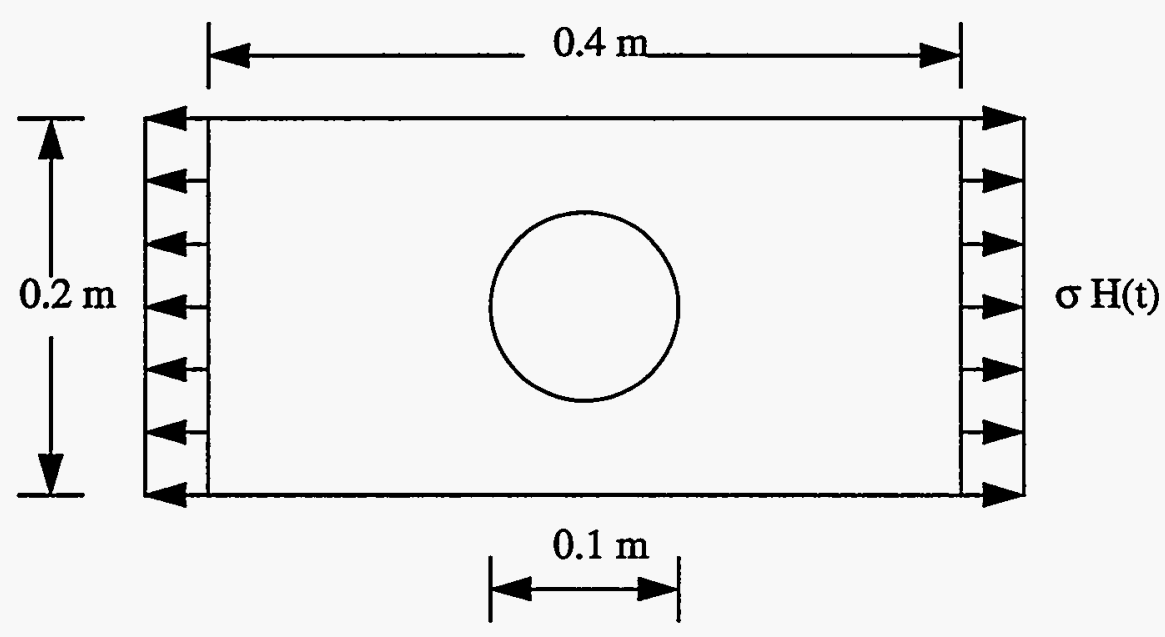

Figure 7. Schematic drawing of the example problem. 
applied symmetrically to the left and right edge of the plate. The plate consists of the same Oil Shale material as the one given in the section on the characteristics of the damage model. For numerical calculations, the pulse is given a strength of $10.0 \mathrm{MPa}$. Both the nonlocal and local damage models as implemented in the finite element code PRONTO 2D are used to obtain the dynamic response of the plate. The plane strain condition is assumed to prevail. Because of symmetry, only one quarter of the geometry in Fig. 7 needs to be included in the finite element mesh. Four meshes with varying degree of fineness are chosen to investigate mesh size effects. Fig. 8 shows the most coarse mesh with 75 elements and 96 nodes. A 90-degree rotation of the schematic drawing in Fig. 7 has been made. The boundary of the hole is divided into 10 elements. The second mesh is constructed by simply doubling the numbers of divisions in both the $\mathrm{x}$ and $\mathrm{y}$ directions in Fig. 8. Thus, the mesh consists of 300 elements and 341 nodes. In a similar expansion, the third mesh is constructed with 1,200 elements and 1,281 nodes. To avoid an excessive number of elements, the fourth mesh only doubles the number of divisions in the third mesh in the lower right part of the plate and consists of 2,800 elements and 2,921 nodes. This is justified because with the applied tensile pulse, the high stress gradients are anticipated to concentrate around the lower right part of the plate and it is not necessary to place fine mesh in other parts of the plate. The finest mesh with 2,800 elements is shown in Fig. 9.

Calculations were carried out on the Cray YMP computer at Sandia National Laboratories. The results of the local continuum model are presented first. The evolution of damage focused on the lower 0.09 -by- 0.09 meter area of the plate is depicted at four time intervals at $0.175,0.2,0.215$ and 0.225 miliseconds after the tensile pulse has been applied. The results are given in Figs. $10-13$, respectively, corresponding to the four meshes. It is clear that damage localizes near the lower right edge of the hole and with more refined mesh, damage localizes into a narrower band. The fact that damage occurs at a direction deviating from the bottom edge of the hole is due to the effect of wave propagation and the strain rate dependence of the damage model. A more detailed explanation is given in [6] and will not be repeated here.

The localization of deformation can also be observed by plotting the distribution of bulk strain around the boundary of the hole. These are shown in Figs. 14-17 for the four meshes at four time intervals. Because the actions are concentrated at the lower right part of the plate, only the lower 45-degree arc of the hole boundary has been included. The bulk strains are the values at integration points of the first layer of elements closest to the hole boundary. The distance is measured counterclockwise from the bottom edge of the hole. Bulk strain localization is clearly observed. Also, the results do not converge with mesh refinement in that the peak strain localizes into a narrower band and attain larger values with mesh refinement.

An additional parameter, namely the characteristic length, is required for the nonlocal calculations. For the present model, the localization limiter is taken to be the radius of the minimum crack that will be activated during the loading process. From the local calculation, the nominal strain rate attained under the applied tensile pulse is approximately $1000 / \mathrm{s}$. Thus, from Equation (7), the minimum crack radius can be calculated and the value is $0.005 \mathrm{~m}$. This value is used for the characteristic length $l$ in Equation (14). This value compares to the minimum dimensions of $0.0196,0.0098,0.00196$, and $0.00098 \mathrm{~m}$, respectively, for the four meshes selected in the calculations. 
Units in meters

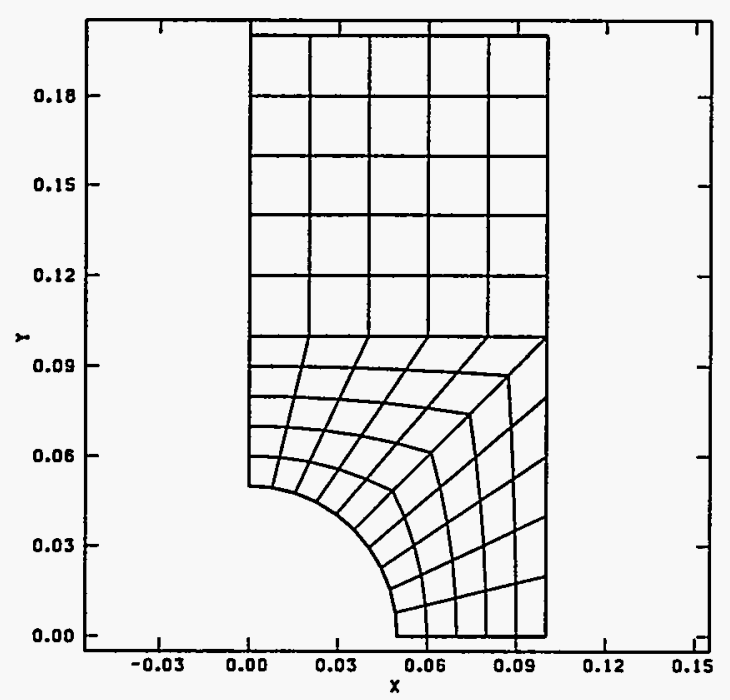

Figure 8. Finite element mesh with 75 elements.

Units in meters

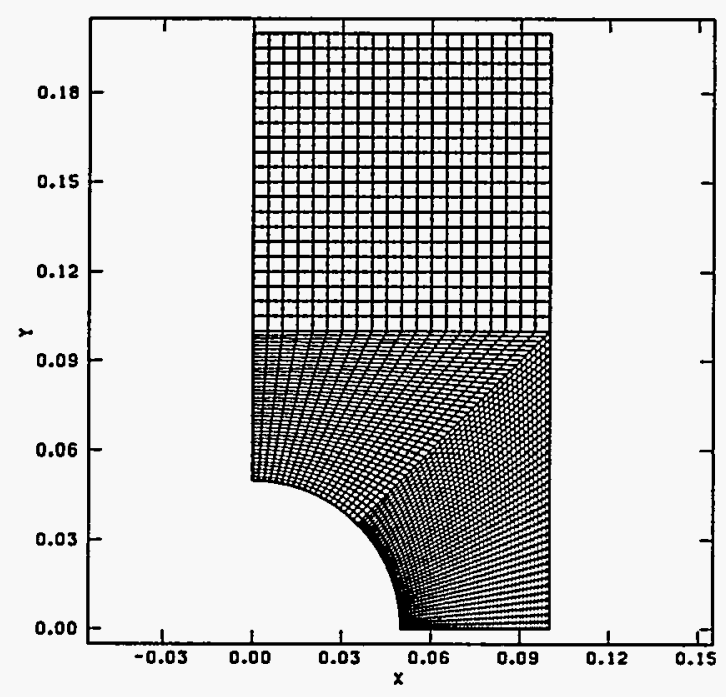

Figure 9. Finest mesh with 2,800 elements. 
The corresponding nonlocal results to those in Figs. $10-13$ are shown in Figs. 18-21. Because the characteristic length is less than the minimum dimension of mesh 1 , the nonlocal averaging will not take effect, and the results in Fig. 18 are identical to those in Fig. 10. When the meshes become progressively finer, the smearing effect of the nonlocal results becomes more pronounced. It is observed that the narrow band of localized damage in Fig. 13 is replaced by lower damage values spread over a wider area near the same location, Fig. 21.

Convergence of the numerical results with mesh refinement is observed from the distribution of bulk strain along the hole boundary. Again, Figs. 22-25 correspond to those in Figs. 14-17. Figs. 24 and 25 show the convergence of bulk strain with mesh refinement. However, the magnitude of the bulk strain is much less than that for the corresponding local calculation. At $0.215 \mathrm{~ms}$, better convergence is achieved in Fig. 24 than the one in Fig. 25 at $0.225 \mathrm{~ms}$. This is attributed to the oscillatory nature of the solution due to pulse loads and the relatively unsophisticated nonlocal formulation adopted here.

\subsection{SUMMARY AND DISCUSSIONS}

The effect of nonlocal continuum formulation on the dynamic damage accumulation process in a brittle solid has been investigated. This study is based on a microcrack based continuum damage model. A nonlocal formulation has been added and the resulting model has been implemented into the transient dynamic finite element code PRONTO 2D for numerical computations. Characteristics of the damage model are presented. The mesh size effect has been studied through a selected example problem.

The nonlocal formulation introduces an additional internal length parameter which must be determined. For the current damage model, this parameter was taken to be the minimum crack dimension which will be activated under the applied pulse load. For other constitutive models, the determination of this length scale may be difficult. Results from the numerical simulations indicate that the nonlocal formulation can yield mesh size independent solutions. However, nonlocality tends to smear out and decrease the magnitude of localized deformation patterns. In many physical situations, such as shear banding, localized and concentrated deformations are physical realities. These characteristics can potentially be lost in nonlocal solutions.

An additional numerical consideration is the selection of mesh size. Based on the present formulation, it is obvious that if the minimum dimension of the finite elements is larger than the characteristic internal length scale, then both local and nonlocal calculation will yield the same result. This is because the nonlocal spatial averaging is extended only to the reach of the internal length scale. Therefore, if the internal length scale can be calculated, then by selecting this length scale to coincide with the least dimension of the finite element mesh, one can use a local formulation to obtain solutions which exhibit a localized zone of correct size and the correct amount of energy dissipation. This may be the reason why many complex local continuum based calculations, such as penetration mechanics analyses [23], do yield reasonable solutions relative to test data. 


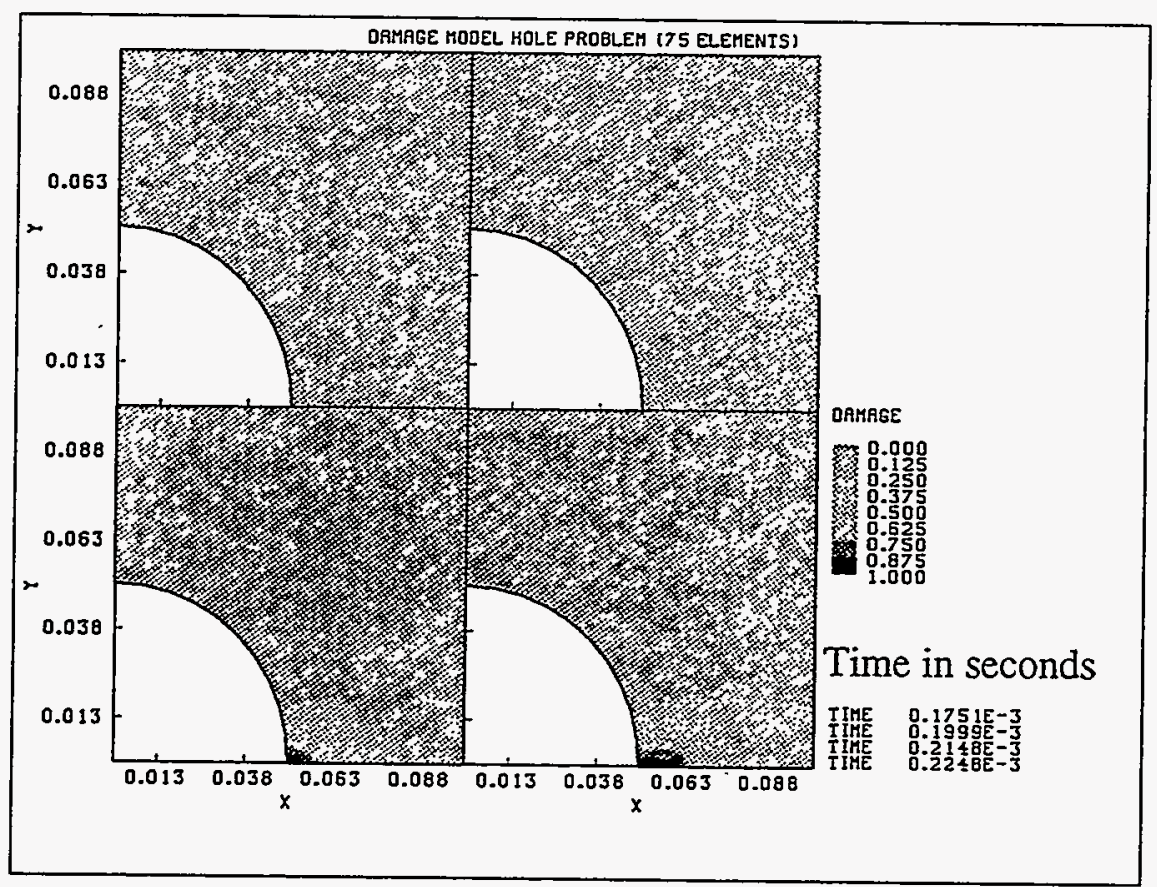

Figure 10. Damage evolution for mesh 1.

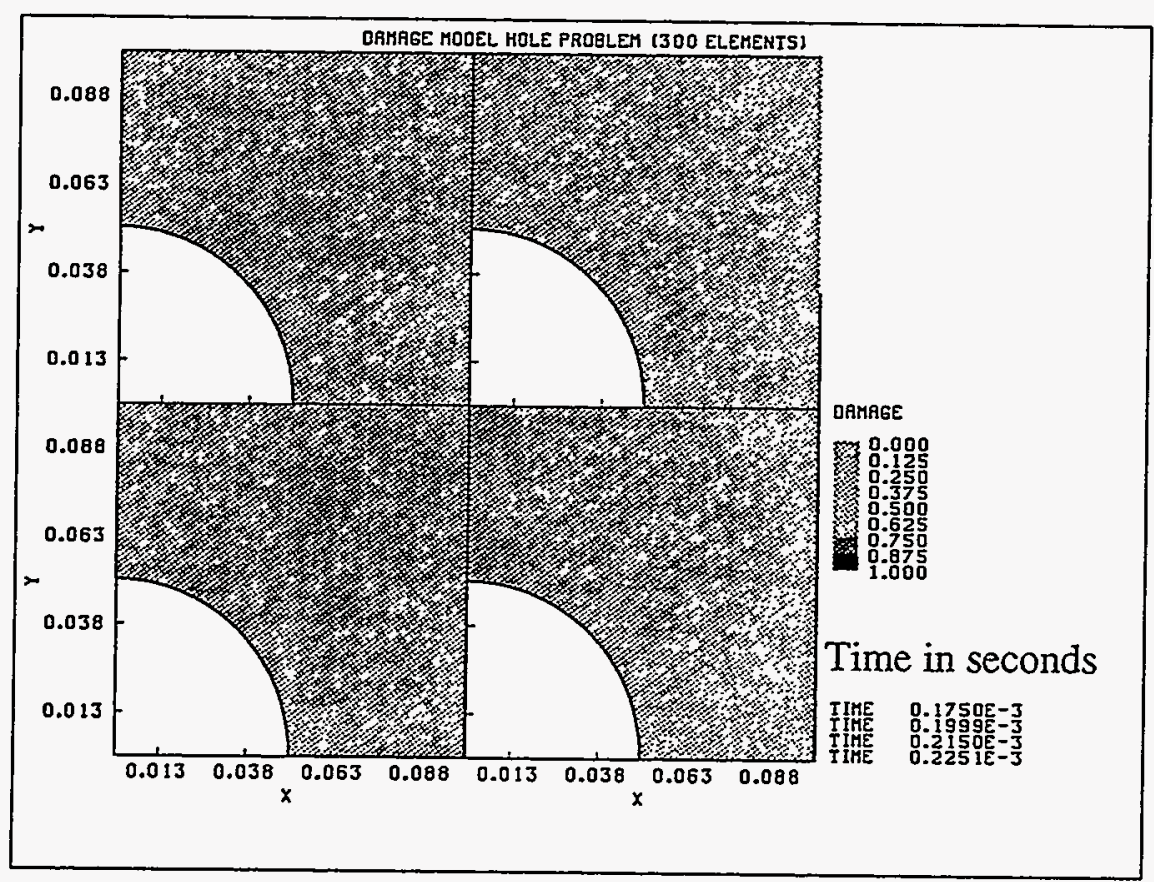

Figure 11. Damage evolution for mesh 2. 


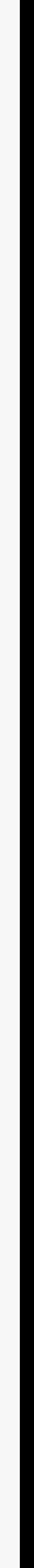




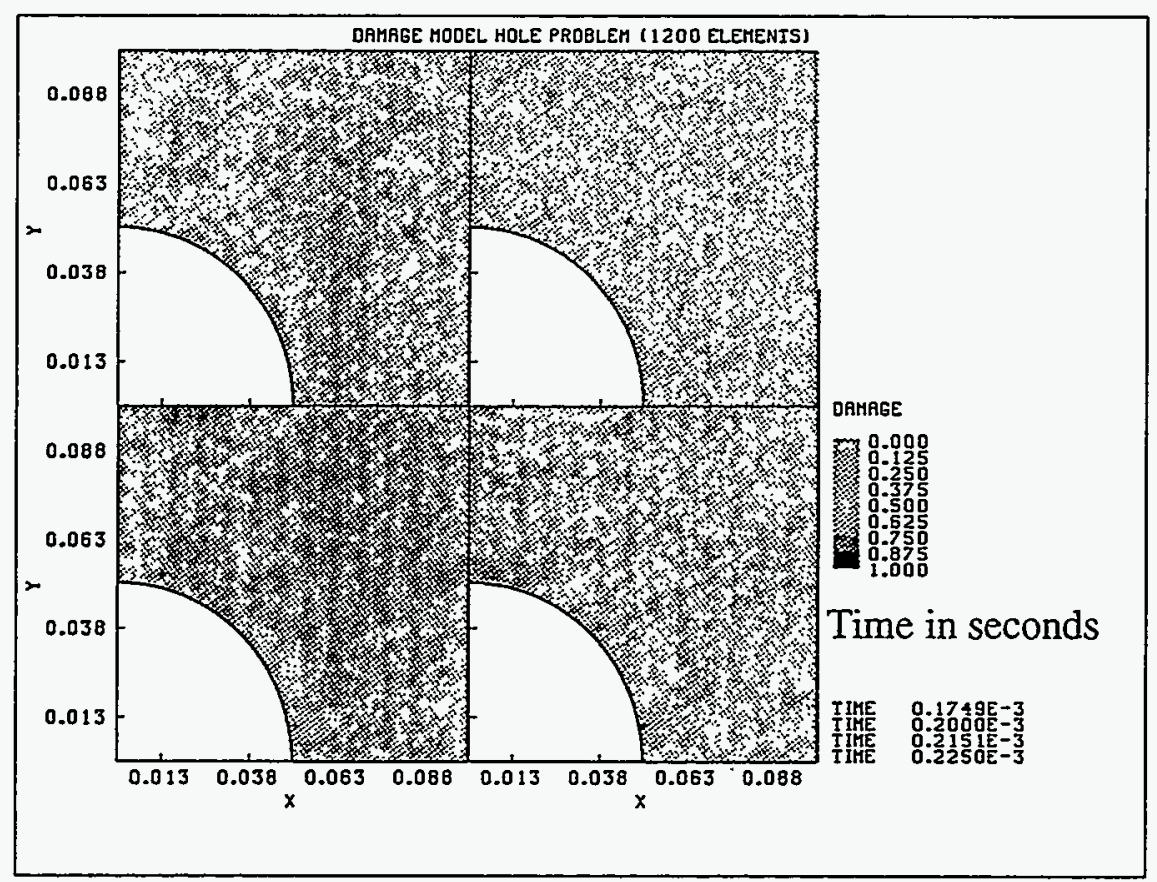

Figure 12. Damage evolution for mesh 3.

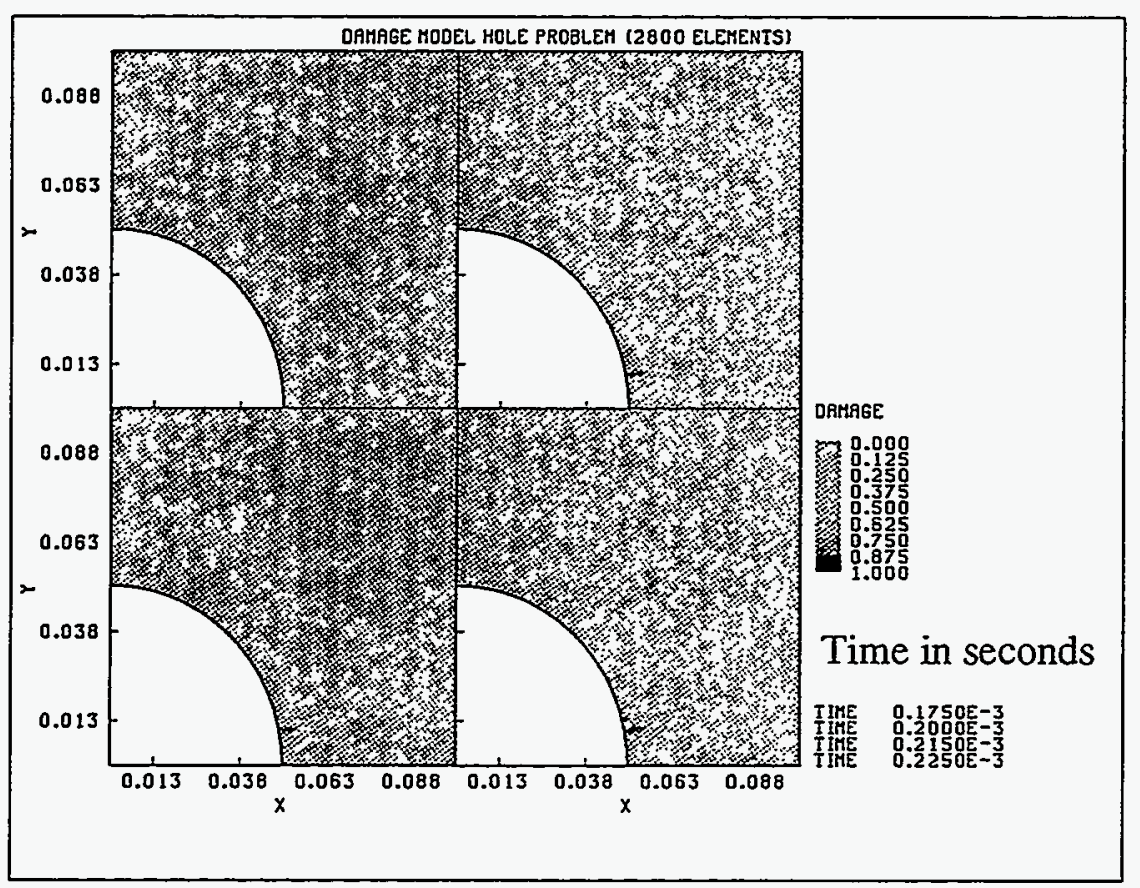

Figure 13. Damage evolution for mesh 4. 


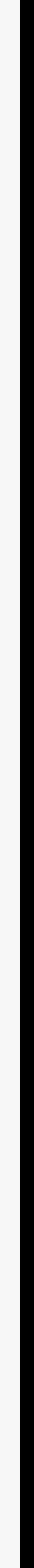




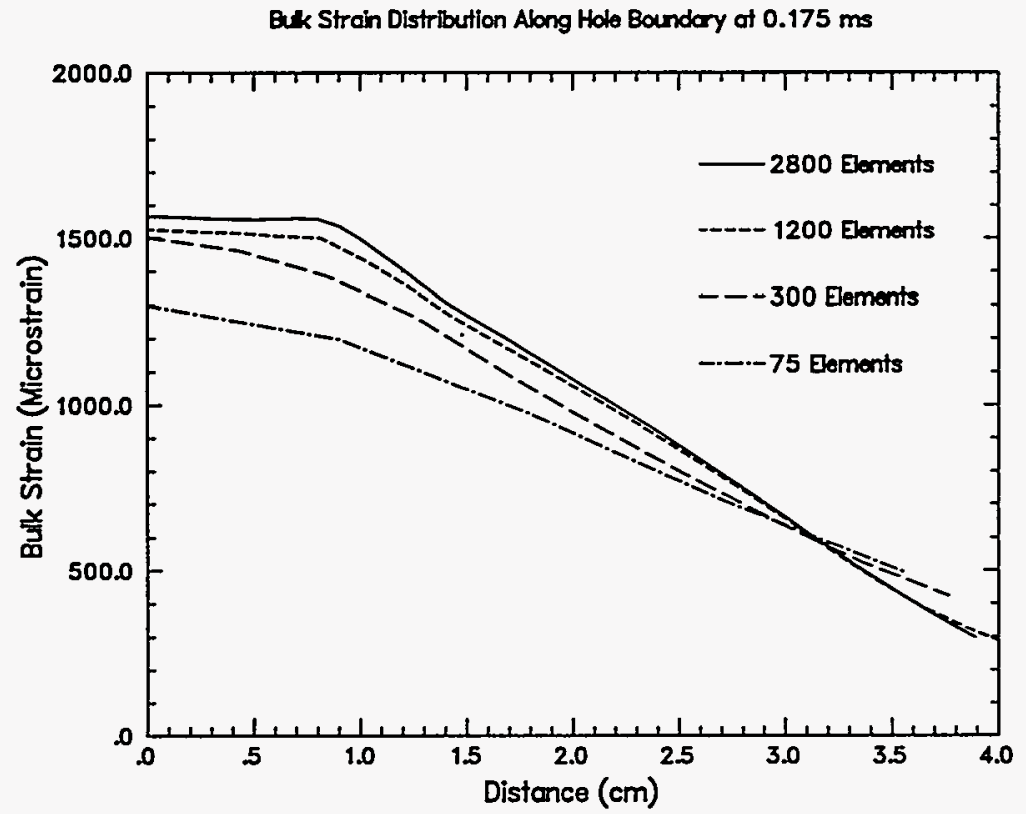

Figure 14. Bulk strain distribution at $0.175 \mathrm{~ms}$.

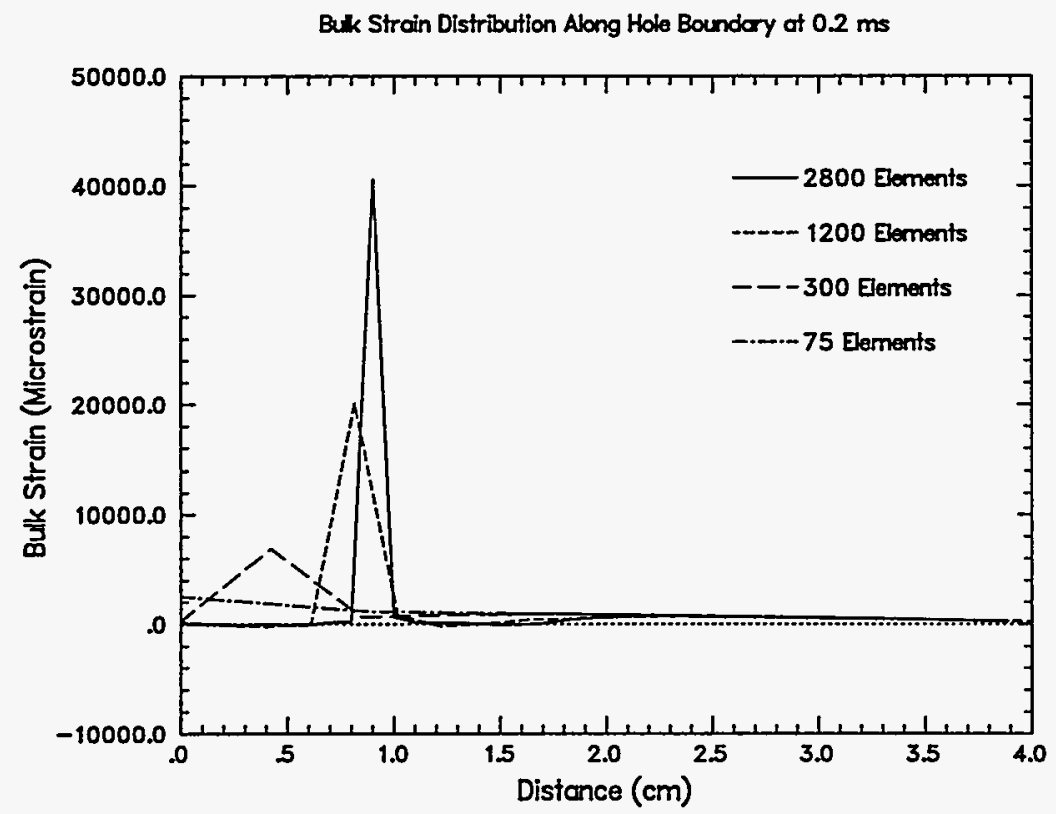

Figure 15. Bulk strain distribution at $0.2 \mathrm{~ms}$. 


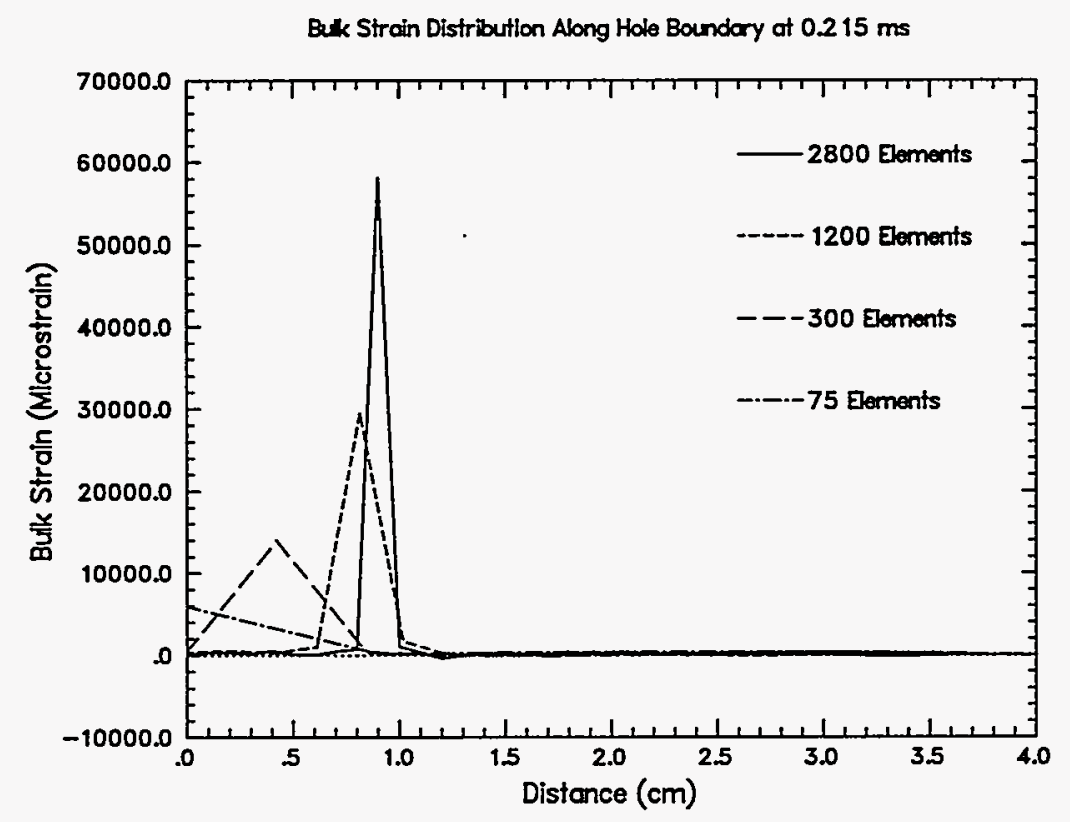

Figure 16. Bulk strain distribution at $0.215 \mathrm{~ms}$.

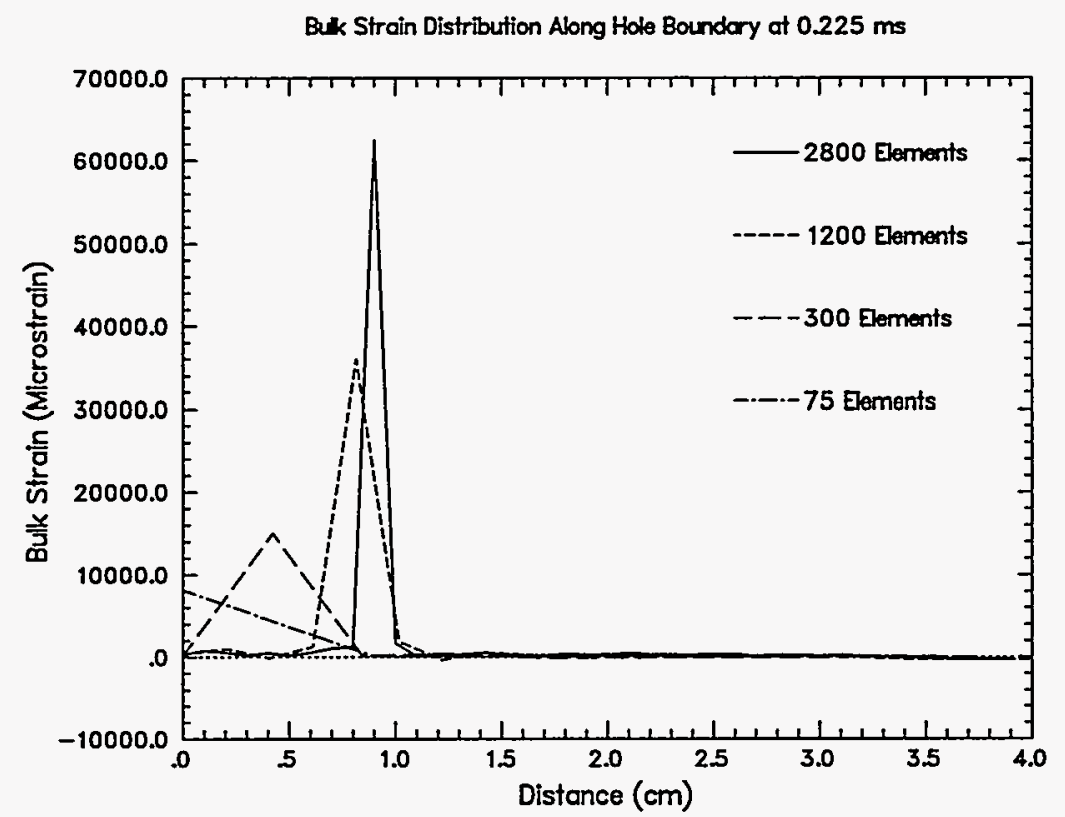

Figure 17. Bulk strain distribution at $0.225 \mathrm{~ms}$. 


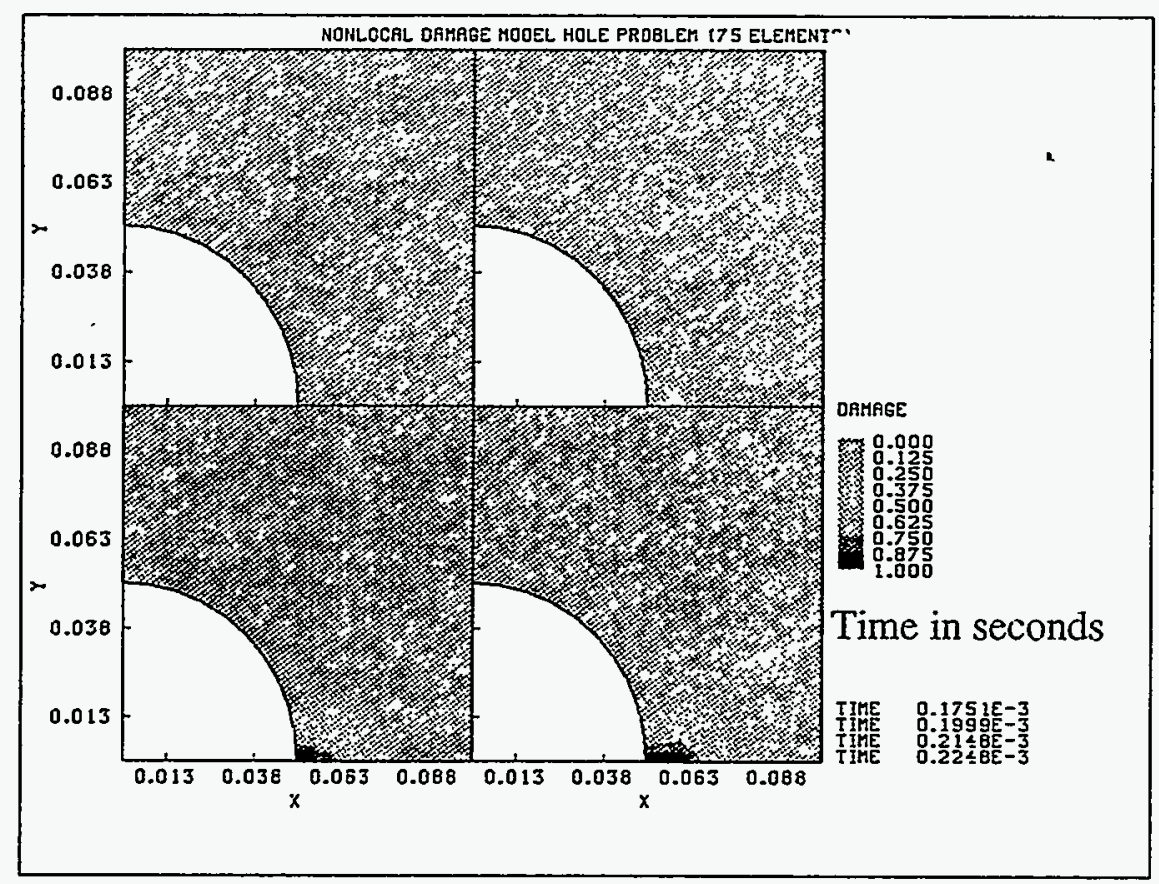

Figure 18. Nonlocal damage evolution for mesh 1.

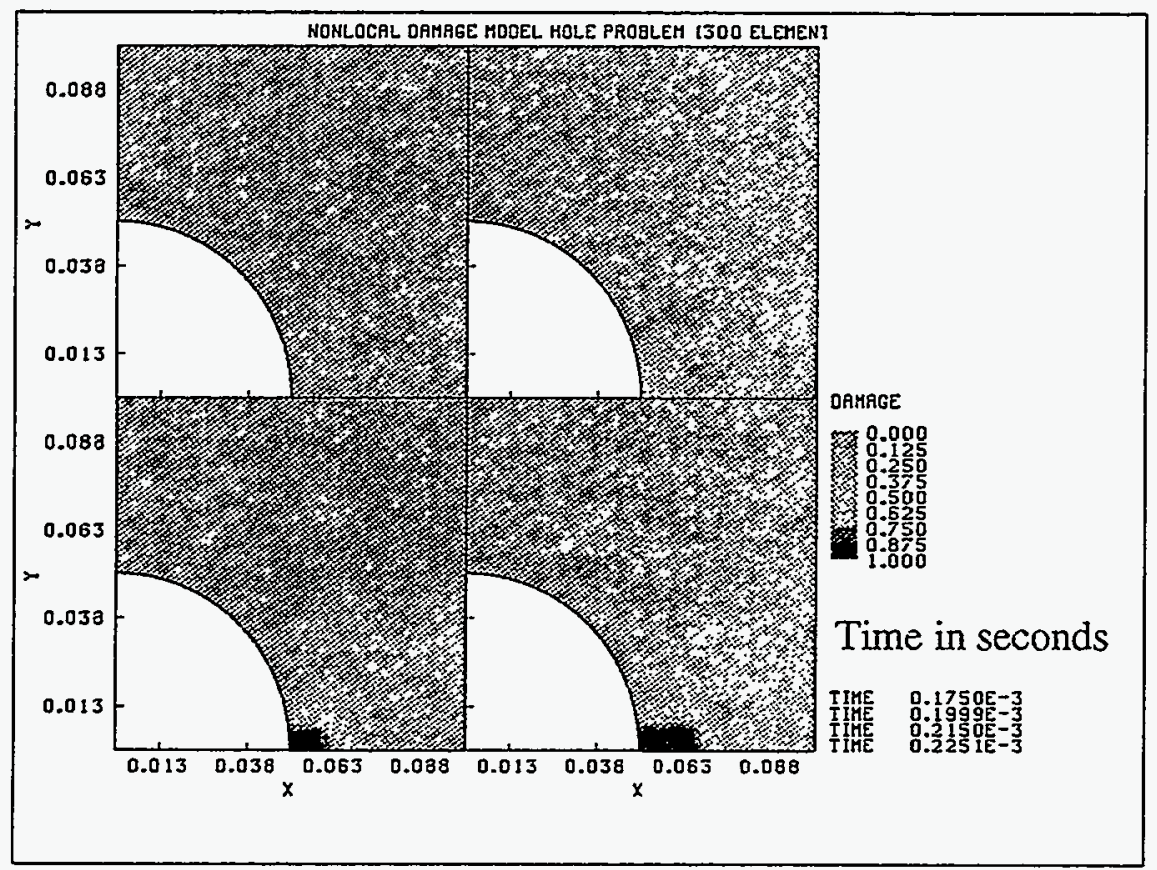

Figure 19. Nonlocal damage evolution for mesh 2. 


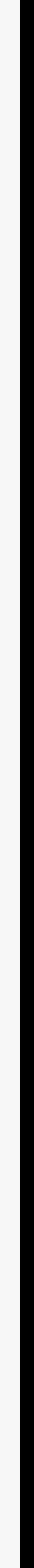




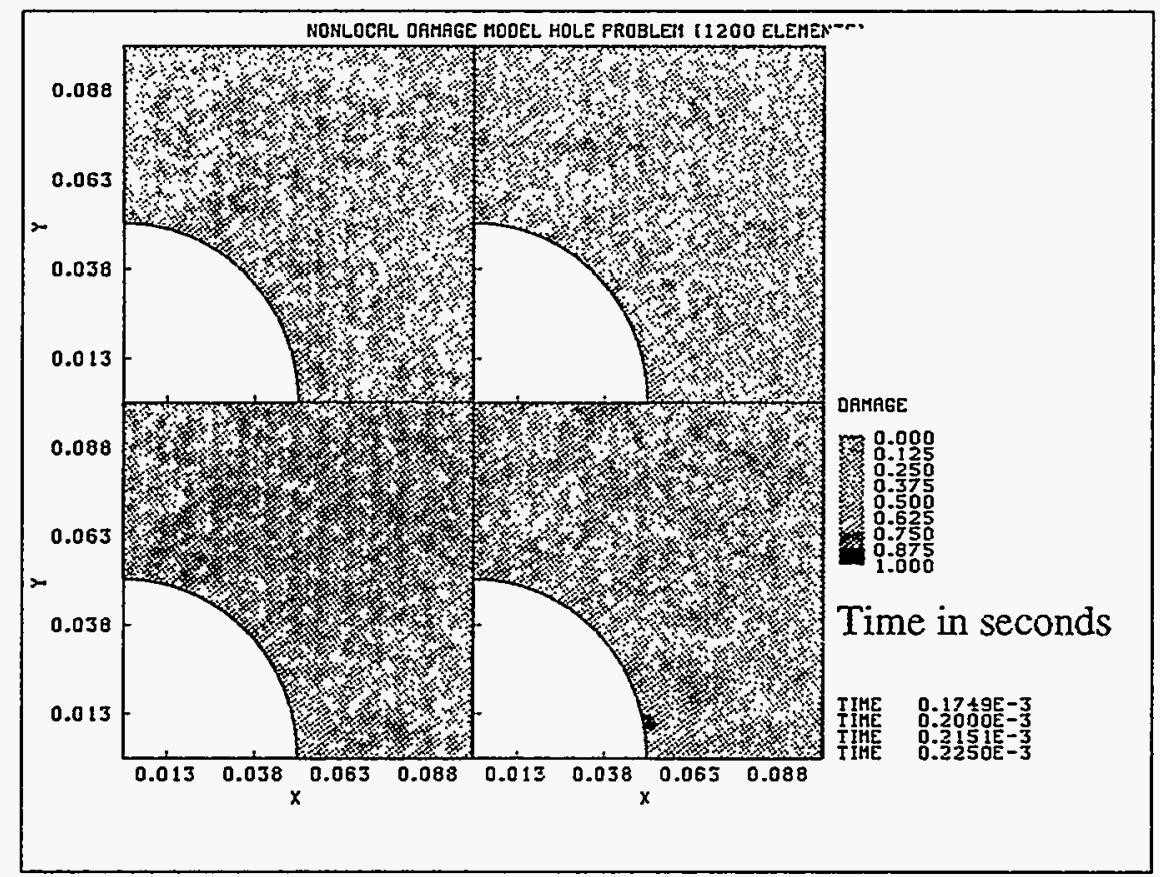

Figure 20. Nonlocal damage evolution for mesh 3.

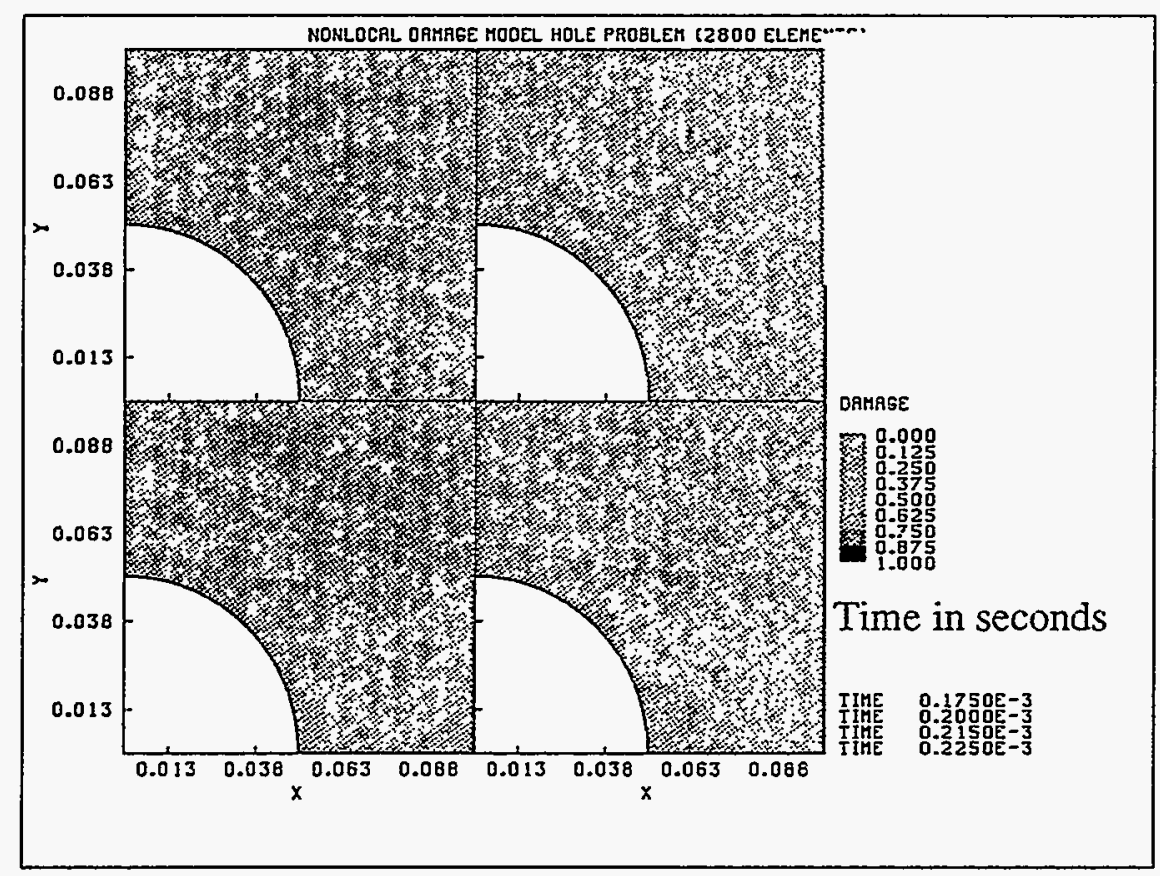

Figure 21. Nonlocal damage evolution for mesh 4. 


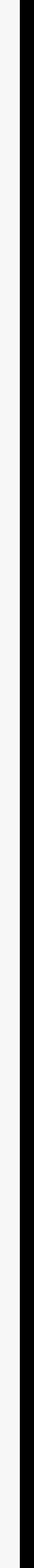


Bulk Strain Distribution Along Hole Boundary at $0.175 \mathrm{~ms}$

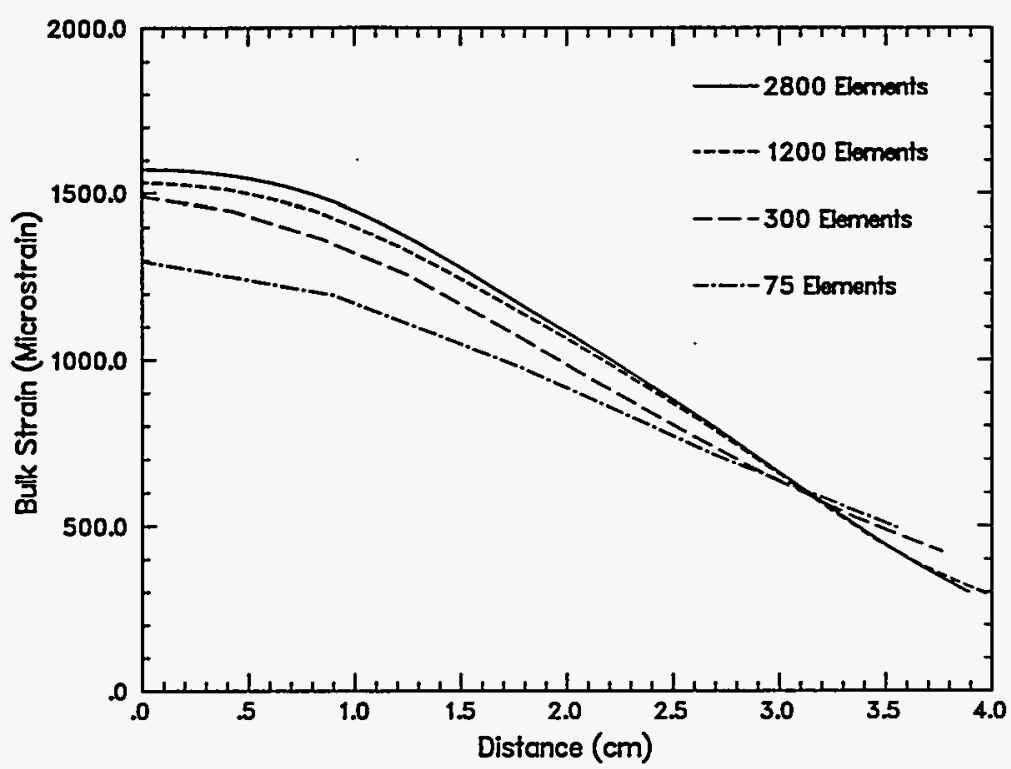

Figure 22. Nonlocal bulk strain distribution at $0.175 \mathrm{~ms}$.

Bulk Strain Distribution Along Hole Boundary at $0.2 \mathrm{~ms}$

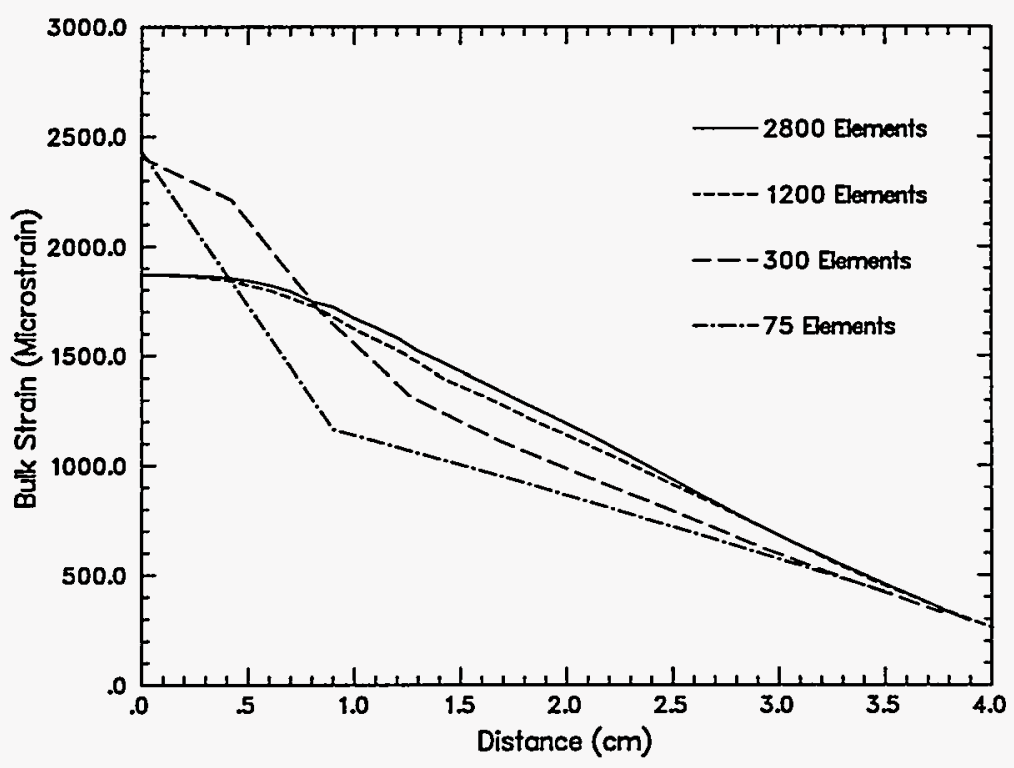

Figure 23. Nonlocal bulk strain distribution at $0.2 \mathrm{~ms}$. 
Bulk Strain Distribution Along Hole Boundary at $0.215 \mathrm{~ms}$

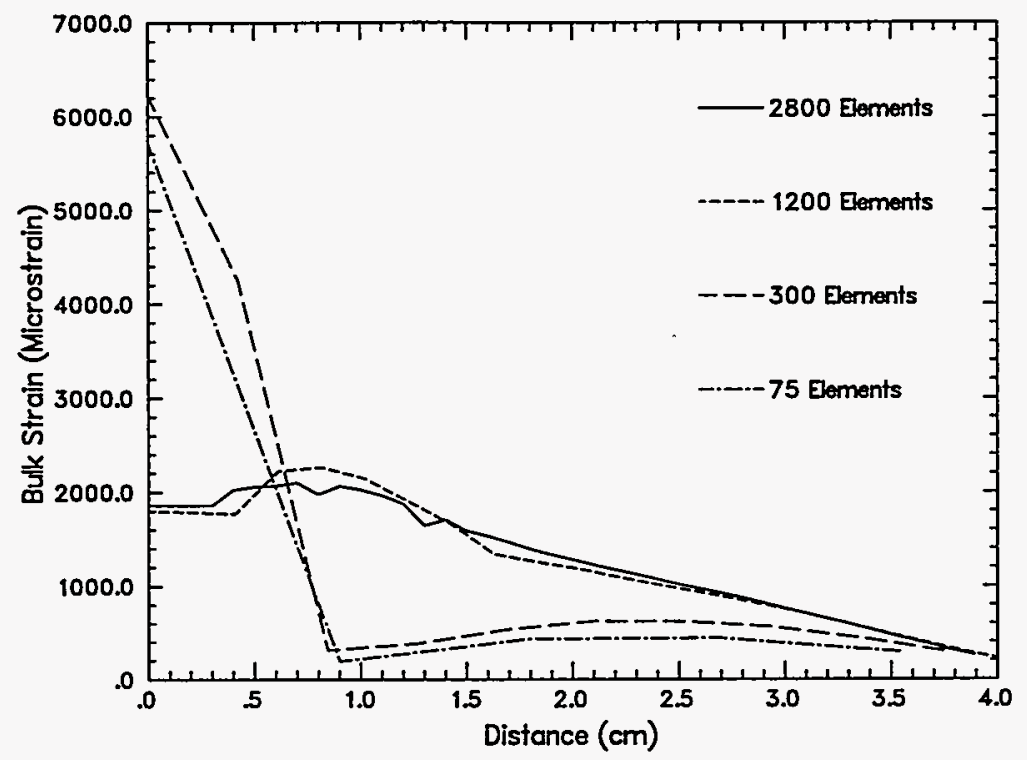

Figure 24. Nonlocal bulk strain distribution at $0.215 \mathrm{~ms}$.

Bulk Strain Distribution Along Hole Boundary at $0.225 \mathrm{~ms}$

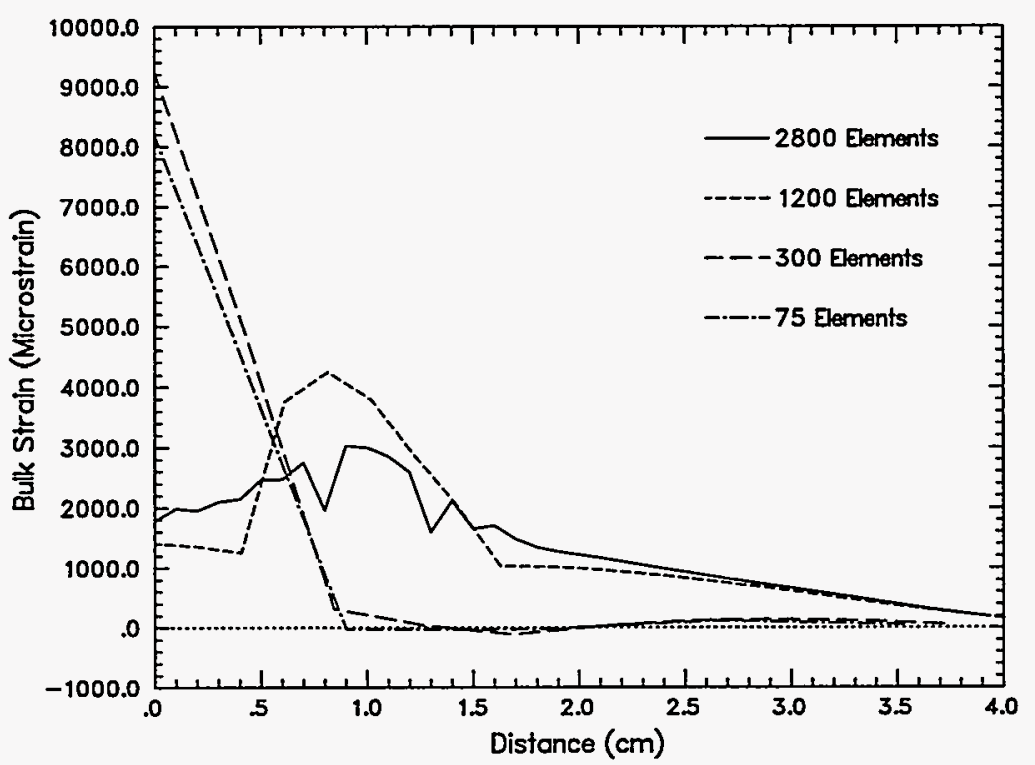

Figure 25. Nonlocal bulk strain distribution at $0.225 \mathrm{~ms}$. 


\subsection{REFERENCES}

1. Taylor, L. M., Chen, E. P., and Kuszmaul, J. S., "Microcrack-Induced Damage Accumulation in Brittle Rock under Dynamic Loading," Journal of Computer Methods in Applied Mechanics and Engineering, Vol. 55, pp. 301-320, 1986.

2. Thorne, B. J., "A Damage Model for Rock Fragmentation and Comparison of Calculations with Blasting Experiments in Granite," Sandia National Laboratories Report SAND90-1389, Albuquerque, New Mexico, 1990.

3. Thorne, B. J., "Application of a Damage Model for Rock Fragmentation to the Straight Creek Mine Blasting Experiments," Sandia National Laboratories Report SAND91-0867, Albuquerque, New Mexico, 1991.

4. Chen, E. P., "Continuum Damage Mechanics Studies on the Dynamic Fracture of Concrete," in Cement-Based Composites: Strain Rate Effects on Fracture, S. Mindess and S. P. Shah, Editors, Materials Research Society Symposia Proceedings Volume 64, Materials Research Society, Pittsburgh, Pennsylvania, pp.63-77, 1986.

5. Chen, E. P. and Taylor, L. M., "Fracture of Brittle Rock Under Dynamic Loading Conditions," in Fracture Mechanics of Ceramics, Volume 7, R. C. Bradt, A. G. Evans, D. P. H. Hasselman, and F. F. Lange, Editors, Plenum press, New York, pp.175-186, 1986.

6. Chen, E. P., "Dynamic Brittle Material Response Based on a Continuum Damage Model," in, R. C. Batra, A. K. Mal, And G. P. MacSithigh, Editors, AMD-Vol. 205, American Society of Mechanical Engineers, New York, pp. 21-34, 1995.

7. Cosserat, E. and Cosserat, F., "Theorie des Corps Deformables," Herman et fils, Paris, 1909.

8. Eringen, A. C. and Edelen, D. G. B., "On Nonlocal Elasticity," International Journal of Engineering Science, Vol. 10, pp. 233-248, 1972.

9. Muhlhaus, H. B. and Aifantis, E. C., "A Variational Principle for Gradient Plasticity," International Journal of Solids and Structures, Vol. 28, pp. 845-858, 1991.

10. de Borst, R. and Muhlhaus, H. B., "Gradient-Dependent Plasticity: Formulation and Algorithmic Aspects," International Journal for Numerical Methods in Engineering, Vol. 35, pp. 521-539, 1992.

11. Pijaudier-Cabot, G. and Bazant, Z. P., "Nonlocal Damage Theory," ASCE Journal of Engineering Mechanics, Vol. 10, pp. 1512-1533, 1987.

12. Bazant, Z. P., "Mechanics of Distributed Cracking," Applied Mechanics Reviews, Vol. 26, pp. 675-705, 1986.

13. Bazant, Z. P. and Lin, F.B., "Non-Local Yield Limit Degradation," International Journal for Numerical Methods in Engineering, Vol. 35, pp. 1805-1823, 1988.

14. Taylor, L. M., and D. P. Flanagan, "PRONTO 2D - A Two-Dimensional Transient Solid Dynamics Program," Sandia National Laboratories Report SAND86-0594, Albuquerque, New Mexico, 1987.

15. Budiansky, B. and O'Connell, R. J., "Elastic Moduli of a Cracked Solid," International Journal of Solids and Structures, Vol. 12, pp. 81-97, 1976.

16. Grady, D. E. and Kipp, M. E., "Continuum Modeling of Explosive Fracture in Oil Shale," International Journal of Rock Mechanics and Mining Science, Vol. 17, pp. 147-157,1980.

17. Grady, D. E., "The Mechanics of Fracture under High-Rate Stress Loading," Preprints of the William Prager Symposium on Mechanics of Geomaterials: Rocks, Concrete and soils, Z. P. Bazant, Editor, Northwestern University, Evanston, Illinois, pp. 149-188, 1980. 
18. Englman, R. and Jaeger, Z., "Theoretical Aids for the Improvement of Blasting Efficiencies in Oil Shale and Rocks," AP-TR-12/87, Soreq Nuclear Research Center, Yavne, Israel, 1987.

19.Drucker, D. C. and Prager, W., "Soil Mechanics and Plastic Analysis or Limit Design," Quarterly of Applied Mathematics, Vol. 10, pp. 157-165, 1952.

20. Kipp, M. E., Grady, D. E. and Chen, E. P., "Strain-Rate Dependent Fracture Initiation," International Journal of Fracture, Vol. 16, pp. 471-478, 1980.

21. Kipp, M. E. and Grady, D. E., "Numerical Studies of Rock Fragmentation," Sandia National Laboratories Report SAND79-1582, Albuquerque, New Mexico, 1978.

22. de Borst, R., Sluys, L. J., Muhlhaus, H. B., and Pamin, J., "Fundamental Issues in Finite Element Analyses of Localization of Deformation," Engineering Computations, Vol. 10, pp. 99-121, 1993.

23. Chen, E. P., "Simulation of Concrete Perforation Based on a Continuum Damage Model," to be published in the Proceedings of the IUTAM Symposium on Size-Scale Effects in the Failure Mechanisms of Materials and Structures, Torino, Italy, October 3-7, 1994. 


\section{Distribution}

\begin{tabular}{lll} 
MS0437 & 9118 & J. B. Aidun \\
MS0437 & 9118 & S. W. Attaway \\
MS0437 & 9118 & E. P. Chen (8) \\
MS0437 & 9118 & J. Jung \\
MS0437 & 9118 & D. Lo \\
MS0437 & 9118 & F. J. Mello \\
MS0437 & 9118 & E. D. Reedy \\
MS0437 & 9118 & J. W. Swegle \\
MS0437 & 9118 & M. R. Tabbara \\
MS0437 & 9118 & R. K. Thomas \\
MS0439 & 9234 & D. R. Martinez \\
MS0441 & 9225 & P. L. Stanton \\
MS0443 & 9117 & R. S. Chambers \\
MS0443 & 9117 & A. F. Fossum \\
MS0443 & 9117 & M. W. Heinstein \\
MS0443 & 9117 & S. W. Key \\
MS0443 & 9117 & H. S. Morgan \\
MS0443 & 9117 & M. K. Neilsen \\
MS0443 & 9117 & C. M. Stone \\
MS0443 & 9117 & G. W. Wellman \\
MS0483 & 5165 & N. R. Hansen \\
MS0819 & 9231 & J. M. McGlaun \\
MS0820 & 9232 & P. Yarrington \\
MS0820 & 9232 & S. A. Silling \\
MS0828 & 9102 & R. D. Skocypec (Route to 9111) \\
MS0828 & 9104 & E. D. Gorham (Route to 9114, 9115) \\
MS0833 & 9103 & J. H. Biffle (Route to 9116) \\
MS0834 & 9112 & A. C. Ratzel (Route to 9113) \\
MS0841 & 9100 & P. J. Hommert \\
MS1436 & 1010 & C. Meyers \\
MS9042 & 8741 & G. A. Benedetti \\
MS9042 & 8741 & M. Chiesa \\
\hline 5743 & D. Bammann \\
MS043 & &
\end{tabular}




$\begin{array}{lll}\text { MS9043 } & 8743 & \text { M. L. Callabresi } \\ \text { MS9043 } & 8742 & \text { P. E. Nielan } \\ \text { MS9043 } & 8742 & \text { L. I. Weingarten } \\ \text { MS9044 } & 8746 & \text { W. A. Kawahara } \\ \text { MS9044 } & 8746 & \text { W. Y. Lu } \\ \text { MS0100 } & 7613-2 & \text { Document Processing for DOE/OSTI (2) } \\ \text { MS0899 } & 4414 & \text { Technical Library (5) } \\ \text { MS0619 } & 12615 & \text { Print Media } \\ \text { MS9018 } & 8523-2 & \text { Central Technical Files }\end{array}$




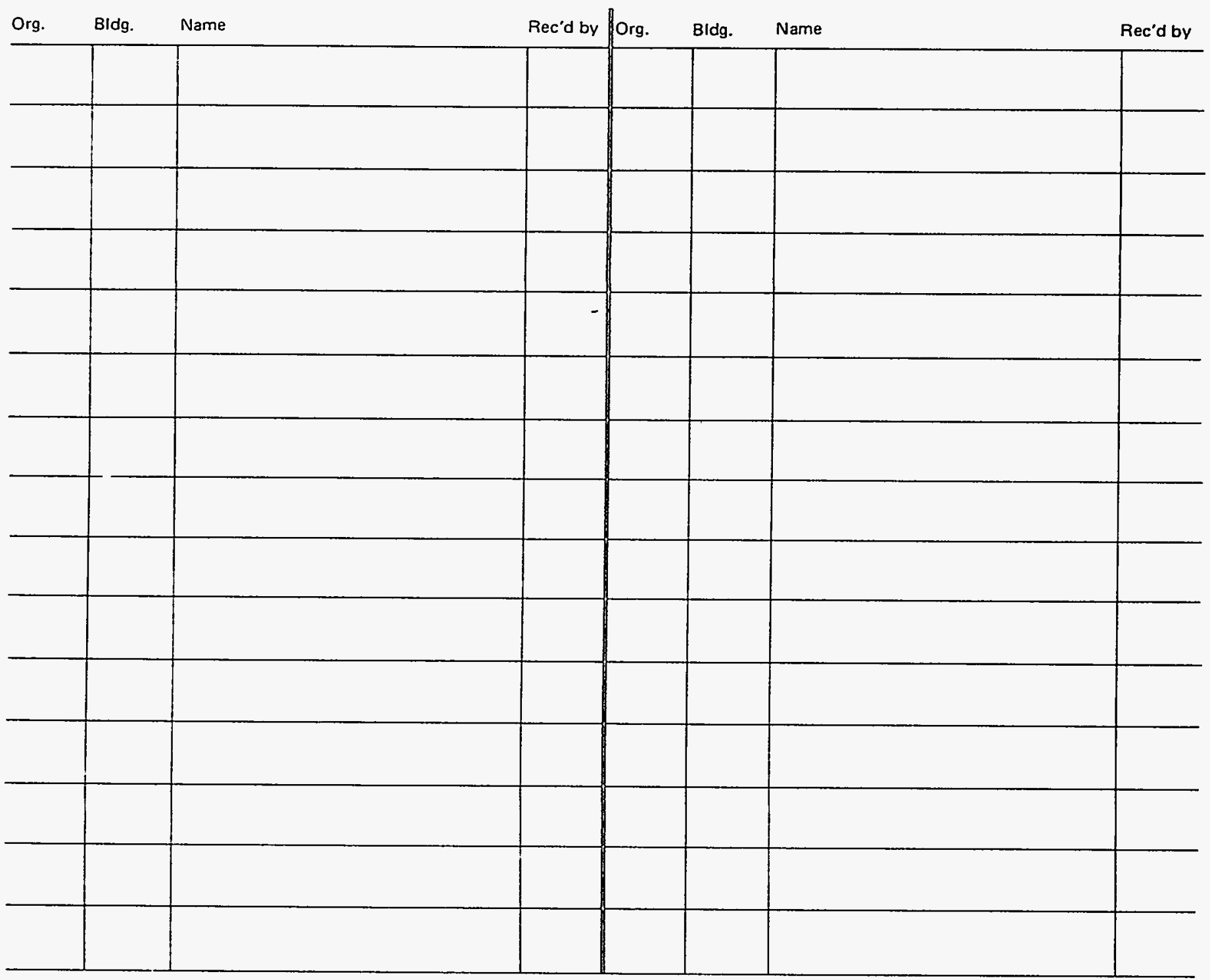

[ra Sandia Natitional Laboratiories. 